NBER WORKING PAPER SERIES

\title{
FAMILY CAP PROVISIONS AND CHANGES IN BIRTHS AND ABORTIONS
}

\author{
Ted Joyce \\ Robert Kaestner \\ Sanders Korenman \\ Stanley Henshaw \\ Working Paper 10214 \\ http://www.nber.org/papers/w10214
}
NATIONAL BUREAU OF ECONOMIC RESEARCH
1050 Massachusetts Avenue
Cambridge, MA 02138
January 2004

The views expressed herein are those of the authors and not necessarily those of the National Bureau of Economic Research.

(C2003 by Ted Joyce, Robert Kaestner, Sanders Korenman, and Stanley Henshaw. All rights reserved. Short sections of text, not to exceed two paragraphs, may be quoted without explicit permission provided that full credit, including (C) notice, is given to the source. 
Family Cap Provisions and Changes in Births and Adoptions

Ted Joyce, Robert Kaestner, Sanders Korenman, and Stanley Henshaw

NBER Working Paper No. 10214

January 2004

JEL No. J1

\section{$\underline{\text { ABSTRACT }}$}

As part of welfare reform efforts in the 1990s, twenty-three states implemented family caps, provisions that deny or reduce cash assistance to welfare recipients who have additional births. We use birth and abortion records from 24 states to estimate effects of family caps on birth and abortion rates. We use age, marital status and completed schooling to identify women at high risk for use of public assistance, and parity (number of previous live births) to identify those most directly affected by the family cap. In family cap states, birth rates fell more and abortion rates rose more among high-risk women with at least one previous live birth compared to similar childless women, consistent with an effect of the family cap. However, this parity-specific pattern of births and abortions also occurred in states that implemented welfare reform with no family cap. Thus, the effects of welfare reform may have differed between mothers and childless women, but there is little evidence of an independent effect of the family cap.

Ted Joyce

NBER

365 Fifth Avenue, 5th Floor

New York, NY 10016-4309

and NBER

ted_joyce@baruch.cuny.edu

Robert Kaestner

Institute of Government and Public Affairs

University of Illinois at Chicago

815 West Van Buren Street, Suite 525

Chicago, IL 60607

and NBER

kaestner@uic.edu
Sanders Korenman

School of Public Affairs

Baruch College

17 Lexington Avenue, Box C-408

New York, NY 10010

and NBER

sanders_korenman@baruch.cuny.edu

Stanley Henshaw

Alan Guttmacher Institute

120 Wall Street

New York, NY 10005

shenshaw@guttmacher.org 


\section{Introduction}

A primary motivation for state and federal welfare reform was the high rate of non-marital fertility and economic dependence among single mothers. State waivers in the early 1990 s gave states authority to implement policies to reduce the need for public assistance. The state waivers were followed by national welfare reform legislation, the 1996 Personal Responsibility and Work Opportunity Reconciliation Act (PRWORA), which adopted many state initiatives and ended the guarantee of long-term cash assistance to single mothers. Components of welfare reform such as time limits, work requirements and sanctions for noncompliance, higher earned-income disregards, and increased child care subsidies were all intended to encourage employment and economic self-sufficiency. Time-limiting benefits and requiring work also increase the cost of childbearing among welfare recipients or potential recipients, and thus may lower the incidence of non-marital birth.

Despite the intentions of policymakers, PRWORA contains few provisions designed specifically to reward marriage or to penalize non-marital fertility. Only the family cap, which permits states to deny or reduce cash assistance for additional births to current recipients, operates directly on fertility incentives. In this paper, we analyze the association between family cap provisions and births and abortions. Our analysis is distinct because it is the only econometric study of the effect of the family cap that analyzes both birth and abortion rates among women at risk for public assistance. Most previous analyses of the effect of welfare reform on fertility behavior have examined only births (Kearney, forthcoming; Joyce, Kaestner and Korenman 2003; Kaushal and Kaestner 2001; Mills et al. 2001; Hovarth-Rose and Peters 2001; Fein 1999; Dyer and Fairlie 2001). ${ }^{1}$ Broadening the analysis of the effects of welfare reform to include abortions as well as births provides additional information on changes in reproductive behavior associated with welfare reform. For example, a fall in birth rates associated with the family cap may be accompanied by a rise in abortion rates (Jaganathan and Camasso 2003; Camasso et al. 2003). Moreover, the fall in birth rates should be expected to

\footnotetext{
${ }^{1}$ Levine (2002) is an exception, but he uses aggregate abortion rates for all adult women; it is questionable, therefore, whether he is able to identify effects of the family cap on women exposed to the policy. Jaganathan and Camasso (2003)
} 
exceed the rise in abortion rates since women affected by welfare reform may also decrease sexual activity or increase contraceptive effort in order to control fertility.

We also estimate the effects of the family cap on pregnancy resolution. Specifically, we investigate whether the fraction of pregnancies that are terminated, henceforth the abortion ratio, increased with the family cap. We recognize that the abortion ratio cannot identify changes in sexual activity and contraception in response to the family cap. However, the abortion ratio has one distinct advantage over measures of birth and abortion rates: it is measured entirely from vital statistics; no population estimates are required for its construction. Therefore, we are able to calculate the abortion ratio and examine the effect of the family cap for small populations with a high proportion of members likely to be affected by the family cap. In addition, pregnancy resolution is of interest because rates of unintended pregnancy and abortion are high among unmarried women. Henshaw (1998) estimates that 75 percent of all pregnancies to teens, and 75 percent of all pregnancies to unmarried women are unintended. In multi-state studies of the family cap, most researchers have used between-state variation to identify effects of the family cap. ${ }^{2}$ Controls for other aspects of welfare reform are included in the regressions or the study period is limited to the pre-TANF years (Hovarth-Rose and Peters 2001; Dyer and Fairlie 2001). A potential limitation of this strategy is that it is difficult to characterize and measure the differences in complex multi-faceted welfare reform programs adopted by different states and enforced to varying degrees (see Moffitt 2003a and 2003b for discussion of these and other evaluation challenges). We use a within-state design to estimate effects of the family cap on births and abortions separate from the impact of other policies related to welfare reform. We use parity ( 0 or $1+$ previous births $)$ to define within-state treatment and comparison groups. Specifically, we compare unmarried adult women with 12 or fewer years of schooling who have no previous live births to similar women who have had one or more previous live births. Both groups have a high likelihood of being affected by welfare reform, but only those of also examine births and abortions but their analysis is unique, since it is based on the experimental evaluation of New Jersey's Family Development Program.

${ }^{2}$ These studies estimate models that include state and year fixed effects with a dummy variable for the state and year in which a family cap policy was implemented. Exceptions are Dyer and Fairlie (2001) and Levine (2002). Dyer and Fairlie 
parity one or higher should be affected by the family cap. ${ }^{3}$ The data used for our analyses were collected through a joint effort of the National Bureau of Economic Research and the Alan Guttmacher Institute. We collected individual induced termination of pregnancy (abortion) records from 24 states and New York City. This is the largest compilation of such data ever attempted. Most states report these data to the Centers for Disease Control and Prevention (CDC), but only aggregates are published annually. ${ }^{4}$ We use the micro-level data from 1992 to 2000 that amount to a registry of abortions performed in each state each year. As such, they provide advantages over social or health surveys that ask questions regarding induced terminations. Survey data available for analyses of the effects of PRWORA on abortions are limited by underreporting and relatively small samples (Klerman 1998).

\section{Previous Research}

The literature on the effects of welfare policy on pregnancy outcomes (births and abortions) can be divided broadly between the pre- and post-welfare reform periods. The pre-reform literature is summarized by Moffitt (1998), who examines fertility, and Klerman (1998), who focuses on abortion. Both reviewers conclude that financial incentives matter: policies that raise the cost of a birth or abortion tend to discourage each outcome. Findings from this literature, however, are hardly robust, and for some questions of interest data are often lacking, especially with regard to abortion.

The implementation of the family cap in numerous states in the 1990s prompted several researchers to re-examine the effects of this policy on fertility. Argys, Averett and Rees (2001), for instance, use a sample of unmarried AFDC recipients from the NLSY (National Longitudinal Survey of Youth) and estimate the association between incremental cash and food stamps for an additional child and the probability of pregnancy, and conditional on pregnancy, the probability of giving birth. Although they find a positive association in

use married mothers with no more than a high school education as a within-state comparison group and Levine uses childless women. In both cases, the analyses are limited to births.

${ }^{3}$ One identifying assumption is that childless women who desire two or more children are not dissuaded from participating in welfare because of the cap. 
some models, they find no effect on pregnancy and birth once they include state-fixed effects. Grogger and Bronars (2001) use data on twins from the 1980 Census to estimate effects of random differences in the number of children, and thus of welfare benefits, on the timing of marriage and subsequent births. They investigate whether time to marriage and time to the next birth are affected by the size of payments for an additional child. They find some evidence that maximum benefits affect fertility among blacks but not whites, and they find no effect of incremental benefits on subsequent higher order births. Fairlie and London (1997) find a positive association between incremental AFDC benefits and fertility among women on AFDC, using the 1990 SIPP (Survey of Income and Program Participation). However, they find a similar association among married women and single women who were not on AFDC. They conclude that the association found for AFDC mothers is spurious.

Explicit tests of the effects of the family cap on fertility are more recent. Two studies have found a statistically significant association between the family cap and fertility and three others have found none (Hovarth-Rose and Peters 2001; Mach 2001; Kearney forthcoming; Dyer and Fairlie 2001; Levine 2002). However, the two studies that report an association have methodological limitations or inconsistent findings that undermine their credibility. Hovarth-Rose and Peters (2001), for instance, use vital statistics to analyze non-marital birth ratios by state and year between 1984 and 1996. They find that the family cap is associated with a nine percent decline in the non-marital birth ratio among teens and a 12 percent decline among adults in models with state and year fixed effects. However, 20 of the 23 states that implemented family caps did so in 1995 or later. Thus, Horvath-Rose and Peters had few post-cap observations in their sample. In addition, some of their other results are counter-intuitive, which raises questions as to the robustness of the specification. For example, they find that minor parent provisions (waivers that condition eligibility among teens on co-residence with a parent), are associated with a large increase in the non-marital birth ratio among adults, while AFDC-UP programs are associated with lower non-marital birth ratios among teens, but not adults.

\footnotetext{
${ }^{4}$ With few exceptions, abortions are tabulated by state and one other characteristic such as age or race. For an example,
} 
Mach (2001) also finds an association between the family cap and fertility. She uses CPS (Current Population Survey) data, but links households in a given year to their interview in the following year. Thus, Mach is able to analyze changes in fertility among women on welfare who are exposed to the family cap compared to their counterparts in states without the cap. She finds that a loss of an incremental benefit of $\$ 50$ is associated with a 19 percent fall in births. But in Mach's sample only 25 women in the 23 states with family caps had an additional birth in the 10-year study period.. Moreover, Mach does not adjust the standard errors for non-independence within states, and thus her estimates appear overly precise.

A forthcoming study by Kearney finds no relationship between the family cap and fertility. She uses monthly national natality statistics stratified by maternal age, education and marital status from 1989 to 1998 to examine the effect of the family cap on births. She finds no evidence that the family cap lowers fertility in models with state and year fixed effects, and instead finds a positive and statistically significant effect of the family cap on the fertility of white and black women aged 20 to 34 years with less than high school education and with at least one previous live birth.

Levine (2002) also uses national natality files and finds no effect of the family cap. Unlike Kearney, however, Levine runs separate regressions of births to women of zero and higher parity. He finds that the cap is associated with a positive and statistically significant effect on births to women of zero parity, but finds no association between the family cap and births to women of higher parity. Thus, births to women of higher parity, the group most affected by the family cap, fell relative to births to women of zero parity, the comparison group, suggestive of an effect of the family cap. However, the difference in coefficients is not statistically significant.

Dyer and Fairlie (2001) also find no association between the family cap and fertility. They use the CPS data to describe the fertility of unmarried women with 12 or fewer years of schooling and at least one child. In their first approach they limit the panel to states that implemented a family cap prior to the implementation of the TANF (Temporary Assistance to Needy Families) program and a set of comparison

see http://www.cdc.gov/mmwr/preview/mmwrhtml/ss4911a1.htm 
states without family caps or any other waiver prior to TANF. Identification comes from a comparison of changes in fertility across cap and non-cap states. They find no association between the family cap and the probability of an additional birth. In the second approach, they use married women with children and 12 or fewer years of schooling as a within-state comparison group. Again they find no association between the family cap and non-marital fertility. The authors also find no effects of the family cap on non-marital childbearing in separate analyses of New Jersey, contrary to both the experimental and non-experimental evaluations described below.

Except for Levine (2002), each of the other studies of the family cap is limited to an analysis of births and none provide convincing evidence of an effect of additional cash assistance for an additional child on fertility. However, recently published results from an experimental evaluation of New Jersey’s Family Development Program provide what many may consider more compelling evidence that the family cap affects the reproductive behavior of welfare recipients.

\section{New Jersey's Family Development Program}

As part of its waiver agreement with the federal government, New Jersey undertook an experimental evaluation of the family cap provision of the New Jersey’s Family Development Program (FDP). Implemented in October of 1992, the FDP was the first in the nation to impose a cap on benefits for women that have a child while on welfare. ${ }^{5}$ The results of the experimental analysis as well as the non-experimental analysis commissioned subsequent to the experiment were published in two reports (Camasso et al. 1998a; 1998b). The experimental results clearly indicate that the family cap altered reproductive choices of welfare recipients. Births fell eight percent or 2.2 births per thousand recipients, and abortions rose 12 percent or 3.2 per thousand, among the experimental group relative to the control group. Effects were greatest for blacks,

\footnotetext{
${ }^{5}$ Neither of the two other experimental evaluations of the family cap has found effects on fertility (Fein 1999; Mills el al. 2001). However, sample sizes in both evaluations were small. In the Delaware's ABC demonstration there were 1027 participants at risk of pregnancy (Fein 1999); in Arizona's EMPOWER evaluation there were fewer than 900 women at risk. Moreover, neither evaluation analyzed abortions presumably because of difficulties in obtaining accurate information on abortion from surveys. See the review by Grogger, Karoly and Klerman (2002).
} 
with births falling 21 percent and abortions rising 32 percent (relative to black controls). There were no statistically significant differences in either births or abortions among whites, but the substantial increase in the use of contraceptives suggests an increased effort to prevent unintended pregnancies (Jagannathan and Camasso 2003).

There were, however, methodological problems and some anomalous findings. The family cap increased the pregnancy rate, despite a statistically significant increase in the use of contraceptive services. Moreover, effects were concentrated among blacks, and only new as opposed to ongoing welfare cases responded to the changed incentives. Critics have also challenged the internal validity of the New Jersey experiment. A survey of participants revealed substantial confusion among women in both experimental and control groups as to who was subject to the family cap. In addition, a small proportion of caseworkers admitted to using discretion in the assignment of cases to treatment and control groups (Loury 2000; Rossi 2000). ${ }^{6}$ Finally, the information provided by the New Jersey experiment is in some respects incomplete, even abstracting from questions of internal validity (see, e.g., Heckman and Smith 1995 for a general discussion of limitations of experimental evaluations, and Moffitt 2003b for a discussion of challenges specific to welfare reform). First, and most obviously, the results pertain to a single state. Second, the effect of the cap in New Jersey is estimated for women on welfare, but the cap may affect other mothers who are at risk of welfare use upon the birth of a child, including welfare leavers. Family cap provisions generally require that women who leave and then return to welfare after a birth must not have received benefits for a specified period before the additional child is eligible for a higher benefit than children born to mothers on welfare (see, for example, http://www.spdp.org/famcap/famcapexempt.htm).

In sum, the results from the New Jersey experiment provide an interesting counterpoint to the nonexperimental studies. The inability to undertake additional experimental studies means that the resolution of

\footnotetext{
${ }^{6}$ In response to critics, the authors of the New Jersey study demonstrate that actual assignment to the treatment or control group and not participants' perception of group assignment is associated with a rise in abortion after the cap (Camasso et al. 2003). In addition, the authors demonstrate that there was no difference in the attrition rate between the experimental and control groups (Jagannathan, Camasso and Killingsworth, forthcoming). This is a significant result since a limitation
} 
disagreements about the effect of family caps requires additional non-experimental studies. Moreover, there is value in extending the analysis of the effect of the family cap on abortion to a larger number of states. Finally, the simultaneous implementation of several welfare reform policies suggests that a within-state comparison group would improve the research design. Indeed, the differences between the experimental and nonexperimental findings may be a result of the use of cross-state comparison groups in the non-experimental studies. We therefore use a large sample of states, a before-after design and with a within-state comparison group to analyze effects of the family cap on birth and abortion rates.

\section{Research Design and Statistical Methods}

\section{Conceptual Overview}

The family cap provides a financial incentive to not have additional children while on welfare. All else constant, we expect the family cap to lower the probability of an additional birth for women affected by the policy (Klerman 1998; Grogger et al. 2002). Birth rates can fall either through increased use of abortions or because of increased use or effectiveness of contraception (including abstinence). Since contraceptive or sexual behavior can change, decreased birth rates could be accompanied by either increases or decreases in the abortion rate. In other words, abortion rates would tend to increase if family cap provisions had little effect on contraception and unintended pregnancies, but abortion rates could decrease if family cap provisions significantly improved or increased contraception and decreased unintended pregnancies. In any case, pregnancies should decrease.

We also examine the effect of the family cap on the abortion ratio (abortions divided by pregnancies). If the family cap causes abortion rates to rise and birth rates to fall, then the abortion ratio should rise. This would be the case if the family cap had relatively little effect on contraception. Moreover, estimated effects of the family cap on the abortion ratio should be consistent with estimated effects of the family cap on abortion

of the research design was the inability to follow women that leave AFDC. They did not discuss effects of potential discretionary assignment. 
and birth rates since changes in the abortion ratio vary directly with changes in the ratio of abortion to birth rates.

The advantage of the abortion ratio is that it is measured entirely with vital statistics and requires no population estimates to calculate. Therefore, we also use estimates of the effect of the family cap on the abortion ratio to check estimates of the effect of the family cap on abortion and birth rates.

Accurate measurement of abortion and birth rates requires population estimates for some small populations that are not currently available. Therefore, estimates that are broadly consistent across the three outcomes suggest that the absence of fully detailed population data does not bias estimates of the effect of the family cap on abortion rates and birth rates.

\section{Empirical Strategy}

A straightforward research design would entail a comparison of birth and abortion rates before and after implementation of the family cap among women affected by the change in policy relative to similar women who were unaffected. It may also be of interest to examine changes in the abortion ratio to see whether the family cap increased the share of pregnancies that were aborted. A major challenge in analyses of the family cap has been to define an appropriate comparison group. Studies based on non-experimental data have identified the effect of the family cap by using states without a family cap as a comparison group (Hovarth-Rose and Peter 2001; Kearney, forthcoming; Dyer and Fairlie 2001; Mach 2001). However, except in Arkansas, the family cap was never an isolated policy. Other policies that were simultaneously implemented such as time limits, work requirements and sanctions for noncompliance may also affect fertility by reducing the benefits associated with childbearing while on public assistance. Moreover, states vary with respect to the strictness of these policies, which further complicates the ability to isolate changes associated with family cap based on changes across states. Finally, states that implement the policy may differ systematically from states that do not, either because of differences in state characteristics that affect fertility 
(e.g., policy differences) or because of differences in populations. Thus, the use of women in non-cap states as a comparison group may be problematic.

We use a difference-in-differences-in-differences (DDD) strategy to identify the effect of family cap provisions on fertility. Among adults, we use low-educated women of zero parity who are not affected by a family cap provision, but who are at risk for public assistance as a within-state comparison group for similar women of higher parity who are affected by the family cap. This difference-in-differences $\left(\mathrm{DD}_{\text {cap }}\right)$ assumes that changes in reproductive choices among low-educated women with no previous live births are a good counterfactual for changes among similar women of higher parity had a family cap not been enforced. However, unmarried women with modest human capital and previous live births are much more likely to be on, or have been on public assistance than their unmarried counterparts with no previous live births. As a result, the response by women of zero parity to waivers and TANF may differ from that of women with previous live births, which would undermine the design. ${ }^{7}$ Our solution is to estimate the same DD in states without family caps ( $\left.\mathrm{DD}_{\text {noncap }}\right)$ to capture changes in births and abortions associated with welfare reform between women of different parity. Subtracting $\mathrm{DD}_{\text {noncap }}$ from $\mathrm{DD}_{\text {cap }}$ yields the $\mathrm{DDD}$ estimate for the family cap.

For teens, however, we limit the analysis to those with one or more previous live births. For teens, schooling and marital status are not useful markers for risk of welfare receipt (that is, since education is not complete and relatively few teens are married, unmarried nulliparous teens with only a high school education are not a high-risk group). Birth rates of teens with no previous live births and those with one or more differ dramatically, and the risk of public assistance use is likely to differ greatly between the two groups. However, those with at least one previous live birth, although a relatively small proportion of pregnant teens, are at very high-risk for public assistance. Therefore, we focus on this group and compare their behavior before and after

\footnotetext{
${ }^{7}$ Grogger, Haider and Klerman (2002) show that the probability of entry into welfare in California fell as much as the probability of exit rose in the 1990s. This suggests that women of zero parity, a proxy for women at risk of entry, may have similar responses to welfare reform as women of higher parity, our proxy for women on welfare who are likely to exit.
} 
welfare reform in states with and without family caps, which is similar to the research design used in most other studies.

We present estimates of both simple and regression-adjusted DDs and DDDs. As described below, we lack detailed population data by state and year for the relevant demographic groups (e.g., parity 0 and parity $>0$ ) used in our analysis. Thus, we do not use birth and abortion rates as the dependent variables in our regression models. Rather, we use the natural logarithm of births and abortions as a dependent variable and include the natural logarithm of state population by age and race (along with other variables) in the regression models. The coefficients of the policy variables measure relative changes in counts of abortions and births, which, adjusted for population, proxy changes in abortion and birth rates. For the abortion ratio, which does not depend on population, we are able to estimate both unadjusted and adjusted estimates of the effect of the family cap.

We illustrate the regression model using the abortion ratio as the dependent variable. The specification is as follows:

$$
\begin{gathered}
(1) \text { abratio }_{\mathrm{ijt}}=\beta_{1} \text { Parity }_{\mathrm{ijt}}+\beta_{2} \text { Reform }_{\mathrm{jt}}+\beta_{3}\left(\text { Parity }_{\mathrm{ijt}} * \text { Reform }_{\mathrm{jt}}\right)+\beta_{4}\left(\text { Capstate }_{\mathrm{j}} * \text { Parity }_{\mathrm{ijt}}\right)+ \\
\beta_{5}\left(\text { Capstate }_{\mathrm{j}} * \text { Reform }_{\mathrm{jt}}\right)+\beta_{6}\left(\text { Capstate }_{\mathrm{j}} * \text { Reform }_{\mathrm{jt}} * \text { Parity }_{\mathrm{ijt}}\right) \\
\\
\sum \phi_{\mathrm{m}} \mathrm{X}_{\mathrm{mjt}}+\gamma_{\mathrm{j}}+\lambda_{\mathrm{t}}+\varepsilon_{\mathrm{ijt}}
\end{gathered}
$$

Let abratio be the abortion ratio in group i, state $\mathrm{j}$ and year of conception $\mathrm{t}$ and let Parity be a dichotomous indicator that is one if the mother has at least one previous live birth; Reform is a dichotomous indicator that is one for the years in which the policies associated with welfare reform are in effect. ${ }^{8} \mathrm{We}$ define reform as either a pre-TANF waiver or TANF. Let Capstate be one if the state imposed a family cap at any time between 1992 and 1999. The specification reflects that the family cap always occurs as either a

\footnotetext{
${ }^{8}$ We use the fraction of months in which a waiver or TANF were in effect in the year that welfare reform was implemented.
} 
waiver or as part of TANF. ${ }^{9}$ In other words, we compare changes in the dependent variable among teens and adult women exposed to welfare reform that includes a family cap to their counterparts exposed to reform but not the family cap. We also include controls for maximum cash assistance for a family of three, the state unemployment rate and the unemployment rate lagged one year as well as state $(\gamma)$ and year $(\lambda)$ effects. Estimates of the DD within-family cap states is $\beta_{3}+\beta_{6}$; the cross-state DD is $\beta_{5}+\beta_{6}$ and the DDD is $\beta_{6}{ }^{10}$

We use the same specification as in equation (1) to analyze the natural log of abortions and births. But for these outcomes, we include the natural log of the state population by age and race on the right-hand-side of equation (1) as a proxy for the more detailed populations classified by marital status, schooling and parity, which are not available by state and year. In some specifications we also include state-specific linear and quadratic trends in order to control for smooth changes in the dependent variable associated with variation in the population. We interpret the coefficients in these regressions as estimates of the relative changes in abortion and birth rates associated with the family cap, with the caveat that these are approximations given the lack of detailed population data.

We use weighted least squares to account for heteroscedasticity in the estimation of equation (1), weighting by pregnancies. We also use robust procedures to adjust standard errors, clustering observations by state, following Bertrand et al. (2002). Clustering by state takes into account that observations for different years within the same policy regime in a state (e.g., before or after reform) are not independent observations.

\footnotetext{
${ }^{9}$ Arkansas implemented a family cap with no other welfare reform provisions prior to TANF.

${ }^{10}$ Using equation (1), let ab be the outcome of interest. Ignoring state and year fixed effects, which fall out after differencing, we obtain the following:

$\mathrm{E}(\mathrm{ab} \mid$ Parity $=1$, Reform $=1$, Capstate $=1)=\beta_{1}+\beta_{2}+\beta_{3}+\beta_{4}+\beta_{5}+\beta_{6}$

$\mathrm{E}(\mathrm{ab} \mid$ Parity $=1$, Reform $=0$, Capstate $=1)=\beta_{1}+\beta_{4}$

$\mathrm{E}(\mathrm{ab} \mid$ Parity $=0$, Reform $=1$, Capstate $=1)=\beta_{2}+\beta_{5}$

$\mathrm{E}(\mathrm{ab} \mid$ Parity $=0$, Reform $=0$, Capstate $=1)=$

First Difference, Parity $1=\left(\beta_{1}+\beta_{2}+\beta_{3}+\beta_{4}+\beta_{5}+\beta_{6}\right)-\left(\beta_{1}+\beta_{4}\right)=\left(\beta_{2}+\beta_{3}+\beta_{5}+\beta_{6}\right)$

First Difference, Parity $0=\left(\beta_{2}+\beta_{5}\right)$

Difference-in-differences (DD) within cap states $=\left(\beta_{2}+\beta_{3}+\beta_{5}+\beta_{6}\right)-\left(\beta_{2}+\beta_{5}\right)=\beta_{3}+\beta_{6}$

Results for non-cap states follow analogously.
} 


\section{Data}

Abortions

We canvassed state health departments between October 2001 and September 2002 in order to obtain induced termination of pregnancy files (ITOP) without personal identifiers. ${ }^{11}$ The characteristics required for our analyses were the mother's age, race, marital status, parity, completed schooling, gestational age of the fetus, and the month and year of termination. Eighteen states have the data needed to analyze changes among unmarried, low-educated women with a previous live birth. For teens, however, we are able to include 24 states because we use only age, race and parity to determine risk of exposure to the family cap. ${ }^{12}$

Figure 1 displays abortion rates, nationally and for our 24-state sample. The top two series are from the Alan Guttmacher Institute provider survey and the bottom series is our 24-state sample as reported by state health departments. Regardless of the source or sample, abortion rates (abortions per 1000 women aged 15-44) declined between 1992 and 2000. Abortion rates fell 17 percent in our 24-states sample as measured by AGI and 20 percent as measured by state health departments. State health departments report approximately 80 percent of the abortions recorded by AGI. This discrepancy appears relatively constant over time.

Discrepancies between the total number of abortions reported by state health departments and AGI vary by state. Table 1 displays abortions by state and source in 1996 for the 24 states in our sample. In 16 states the difference is less than 10 percent; in four states the difference is between 10 and 15 percent; and in three states the difference exceeds 35 percent. Henshaw (2000) offers various explanations for the differences in total abortions between AGI and state health departments. Most explanations pertain to staff turnover or inexperience as well as provider fear of harassment. However, without additional information, it

\footnotetext{
${ }^{11}$ As noted, the project was a joint effort between researchers at the National Bureau of Economic Research and the Alan Guttmacher Institute.

${ }^{12}$ Table 1 in the Appendix displays the results of our data collection. The first three columns list the 31 states from which we have collected individual-level data on induced abortion. The 20 states listed in the right-hand column will not release or do not collect information on induced abortion at the individual level with sufficient detail for our purposes. Data for 18 of the 31 states for which we have data are complete with respect to age, race, marital status, schooling and parity (column 1). The seven states listed in column 2 lack some combination of these characteristics, whereas the states listed in column 3 have more severe limitations.
} 
is not possible to determine whether the discrepancy in the number of abortions between AGI and the state health departments is related to characteristics of the women, and how this might vary over time.

Certain characteristics of women are reported more completely in the data than are others. In Table 2 we show the number of abortions in each state between 1992 and 2000, and the percent of observations missing by characteristics of the mother. The most problematic characteristic is education. In six of the 18 states that consistently report education, the proportion unknown exceeds 10 percent. The second-to-last column displays the percent of total observations dropped due to missing data for one or all of the characteristics. In the sample of 18 states and New York City, we lose 16 percent of observations in analyses that use education, age, race and marital status. In the 24-state sample that is limited to teens, we lose only seven percent of the observations since we do not use education and marital status. What is not shown in Table 2 is that the proportion of observations missing varies over time due primarily to missing data on education, which is potentially problematic in the pre-post analysis of adult women. We can do little about the missing data; however, births among adults are well reported and thus a significant decline in births unaccompanied by a change in abortions would raise concerns as to the quality of the abortion data. In addition, we do not use education in the analysis of teens.

\section{Births}

Information on births is from national natality files. The main measurement issue of concern relates to marital status in New York and Nevada. ${ }^{13}$ Due to a change in the methods used to determine marital status, out-of-wedlock births in New York City declined almost 10 percentage points between 1996 and 1997 (New York City Department of Health 1998). Similar though smaller changes occurred in Nevada. The problem is limited to births since marital status on New York City and Nevada induced termination certificates has always

\footnotetext{
${ }^{13}$ In New York, marital status of the mother is inferred from a paternity acknowledgment or missing father's name on the birth certificate. Prior to 1996, Nevada and New York City depended on a comparison of the mother's and father's surnames. In 1997, Nevada changed from inference to a direct question and New York City changed to an inferential system comparable to upstate New York. In New York City the proportion of births to unmarried women tended to increase among women aged 15-24 years but decrease among women 30-34 (National Center for Health Statistics, 1999).
} 
been based on a direct question. The change in New York will not affect our estimates since we use New York only in the teen sample and in these analyses we use all births regardless of marital status.

\section{Population}

We use population estimates to obtain birth and abortion rates. We use three sources of population data. We use population estimates by state, year, age and race from the US Census Bureau website for annual birth and abortion rates. These are the most accurate, but are not available by the level of disaggregation (by marital status, schooling, and parity) we require. We therefore use population estimates from the Current Population Survey (CPS) to create annual birth and abortion rates by state, year, age, race, marital status, and schooling for the 18 states in our adult sample. Estimates for a particular year are the weighted average of the outgoing rotation files from the 12 monthly surveys. Finally, we use the June CPS fertility modules in 1992, 1994, 1998 and 2000 to create population estimates further stratified by parity. We estimate rates only for aggregates of states in the time-series plots and simple DDs. Population estimates are not reliable enough at the level of the individual state for the desired subgroups (i.e., age, race, marital status, schooling and parity) to permit regressions of birth and abortion rates.

We focus on three outcomes: birth rates, abortion rates and the abortion ratio defined as the fraction of pregnancies (births plus induced abortions) that end in abortion. We also discuss pregnancy rates, which are the sum of birth and abortion rates. Each outcome is dated to the year of conception. We subtract gestational age from the date of the birth or abortion to approximate the date of conception. Thus, the final year of the analysis is labeled 1999, although many of the births and some of the abortions occurred in 2000 . 


\section{Samples}

We analyze two samples: adult women 20 to 34 years of age who are unmarried and who have completed no more than 12 years of schooling, and teens, 15 to 19 years of age. ${ }^{14}$ We exclude women aged 35 and older because only about 10 percent of all abortions occur at these ages (Koonin et al. 1999), and sample sizes become small when stratified by race, schooling, marital status and parity. We analyze teens separately because for teens we use only parity to define teens at risk for public assistance. Furthermore, since we don't require information on education or marital status for teens we are able to expand the number of states in our sample from 18 to 24 . We analyze whites and blacks only, because, except for New York City, none of the states in our adult sample has a sizeable Latino population.

\section{Dependent and Policy Variables}

Information on family cap policies are from Assistant Secretary for Planning and Evaluation of the Department of Health and Human Services and the State Documentation Project of the Center on Budget and Policy Priorities (www.cbpp.org and www.spdp.org/tanf.htm). Our definition of states with the family cap agrees with those of Kearney (forthcoming) and Dyer and Fairlie (2001), except for two minor differences with respect to the date of implementation.

\section{Results}

Time-series: birth and abortion rates

Figure 2 shows abortion and birth rates (per thousand women) by year of conception for unmarried women 20 to 34 years of age and with 12 or fewer years of schooling. The population denominator for these

\footnotetext{
${ }^{14}$ As Kearney (forthcoming) and Joyce, Kaestner and Korenman (2003) have shown, approximately 50 percent of unmarried mothers with less than 12 years of schooling received public assistance in the previous year. To further characterize these women, in Appendix Table 2 we present data on the percent of births and abortions to women on Medicaid in 1994, a proxy for women at risk for public assistance. Data on Medicaid-financed births comes from the Pregnancy Risk Assessment Monitoring System (PRAMS) from 10 states. For abortions, we use AGI's nationally representative survey of women that abort (Henshaw and Kost 1996). Two points are noteworthy. First, schooling and
} 
rates is from the annual CPS outgoing rotation files, since we do not stratify by parity. Both birth and abortion rates turn slightly upwards after 1996 but the rise in birth rates is somewhat more pronounced. Births started to rise in 1994 and exhibit a slight acceleration in 1996. The minor increase in the abortion rates, however, is counter to a generally downward trend among women in this socioeconomic stratum, and is clearly counter to national trends in abortion (Figure 1). The rise in the birth rate, however, is inconsistent with a behavioral response to welfare reform, which would suggest a decrease. ${ }^{15}$

Figure 3 presents birth and abortion rates for teens for states with and without family cap policies. ${ }^{16}$ Birth and abortion rates trend downward over the 1990s, but the level and trend in each are similar in states with and without family caps. ${ }^{17}$

\section{Difference-in-differences in Rates}

Tables 3 and 4 present abortion and birth rates for teens and unmarried adult women 20 to 34 years of age with 12 or fewer years of schooling, by parity, for periods before and after welfare reform. We use the June CPS fertility module in 1992 and 1994, to estimate population in states with and without family caps in 1992-1993 and the June CPS fertility module in 1998 and 2000 to estimate population in 1998-1999. There are 24 states for the teen sample and 18 states for the adult sample.

Birth rates are defined as births per 1000 women of the specific demographic group and are shown in Table 3. For teens, we show birth rates for all teens and teens with one or more previous live births. Teen birth rates fall in absolute and relative terms over the period but the decline among teens of parity one or more is particularly sharp and greater in states with a family cap (57 percent versus 40 percent).

\footnotetext{
marital status effectively characterize women at risk for public assistance; and second, women with a previous live birth are at greater risk than women with no previous live births.

${ }^{15}$ Birth and abortion rates by race are shown in Figure A1 of the Appendix. The only notable difference is that the abortion rate increases more among blacks after 1996 than among whites.

${ }^{16}$ We are able to present rates stratified by cap and non-cap states because we are not disaggregating by schooling and marital status. Population by age and race are available from the census.

${ }^{17}$ We present rates for teens by race in Figures A2 and A3 of the Appendix. The pattern for whites and blacks is largely similar. The one difference is that the black teen abortion rate is substantially greater in states without a family cap, although trends in the two groups of states are similar.
} 
For less educated and unmarried adults, the lower half of Table 3 shows birth rates for all parities, women of zero parity and women with one or more previous live births. We view women of zero parity as an appropriate comparison group for women of parity 1 or more. Among adults, birth rates decline more among higher parity women than women of zero parity in absolute terms, but the relative decline (DDs), -0.10 and 0.12 , is similar in states with and without family caps.

We display similar changes for abortion rates in Table 4. As with births, we observe a general decline in abortion rates of all teens but the decline among teens of parity one or more is greater in absolute terms but roughly similar in relative terms. Again, the fall in abortion rates among teens with at least one previous live birth is relatively greater in states with a family cap ( 57 versus 40 percent). The lower panel of Table 4 shows the same estimates for adult women. In this case, abortion rates fall less for higher-parity women than for zero-parity women in states with a family cap and abortion rates rise among higher parity women in states without a family cap. The DD in relative terms is positive in states with family caps $(0.286)$, but is also positive in states without family caps $(0.253)$.

We also compute changes in pregnancy rates, which are displayed in Table A3 of the Appendix. Changes in pregnancy rates are weighted sums of changes in birth and abortion rates. The DD estimates for the adult pregnancy rates are essentially zero. Among teens of parity one or more, pregnancy rates decline over the study period, and the decline is greater for teens in states with a family cap than in states without. Pregnancy rates among adults in states with a family cap fall over the study period but the relative decline is the same by parity. In states without family caps pregnancy rates rise slightly but there is no difference by parity.

The importance of analyzing both abortion and birth rates in states with and without a family cap is underscored by results in Tables 3, 4 and A3. For adults, the within-state DDs for birth and abortion rates within family-cap states are largely consistent with an effect of the family cap: a decrease in birth rates, a relative increase in abortion rates, with no change in relative pregnancy rates. But the same pattern is observed in states without a family cap. Taken together, changes in birth and abortion rates among adult women exposed to the family cap is more consistent with general trends in reproductive choices among lesser-skilled 
women, than a specific response to the family cap. The results for teens were similar in that there was a general decline in birth and abortion rates among teens in states with and without a family cap.

\section{Abortion Ratios}

We display abortion ratios by years of conception, cap and non-cap states, and parity, for teens and unmarried adult women with 12 or fewer years of schooling in Table 5. The change in the abortion ratio can be obtained from knowledge of the relative change in abortion and birth rates, which provides a consistency check for the analysis. When the relative decline in the birth rate exceeds the relative decline in the abortion rate, the abortion ratio rises. Thus, the abortion ratio among teens of parity one or more in states with a family cap is unchanged between 1992-93 and 1998-99 (Table 5, top panel), since the relative decline in birth and abortion rates is the same over this period (Tables 3 and 4, top panel). However, the within-state DD for adult abortion ratios in Table 5 is positive and large because the relative decline in birth rates greatly exceeds the fall in abortion rates among women of zero parity. Thus, the simple DD for the adult abortion ratio is consistent with a negative effect of the family cap on fertility. This interpretation, however, is again undermined by similar changes in states without family caps. The simple DD for adults in non-cap states is also positive and of equal magnitude to the DD in states with a family cap. Thus, welfare reform or other contemporaneous influences, but not the family cap in particular, may have increased abortion more at higher parities. ${ }^{18}$

The simple DDs in Tables $3-5$ describe changes in reproductive choices before and after the recent waves of welfare reform and implementation of family cap provisions. To more accurately associate changes in births and abortions with the timing of various policies we turn to the estimation of equation (1). An important advantage of the abortion ratio is that we have counts of births and abortions in our sample states and are able to construct a panel by state, year, age, schooling, marital status, parity and race. Consequently, we obtain estimates of the association between changes in the abortion ratio and the implementation of welfare reform

\footnotetext{
${ }^{18}$ This might be expected if welfare reform, for example, reduced desired family size among high-risk women, but did not affect the timing of first births. We explore the more general effects of welfare reform in a companion paper that does not look explicitly at the family cap (Joyce et al. 2003).
} 
and the family cap adjusted for other covariates as well as state and year fixed effects. We also present estimates based on regressions of log abortions and log births adjusted for aggregate population totals as proxies for regressions of abortion and birth rates, respectively.

\section{Regression Adjusted Estimates}

Estimates of equation (1) by age and race are displayed in Table 6. There are three outcomes: the natural logarithm of abortions, the natural logarithm of births and the abortion ratio. For adults we present three estimates: the $\mathrm{DD}$ in states with family caps $\left(\mathrm{DD}_{\text {cap }}\right)$, the $\mathrm{DDD}$; and the cross-state $\mathrm{DD}\left(\mathrm{DD}_{\text {cross-state }}\right)$. The latter is obtained by comparing changes among women of parity one or more in states with a family cap to changes among similar women in states without a family cap. For teens we show only the cross-state DD. For adults we find statistically significant evidence consistent with an effect of the family cap if we examine only states with a family cap. Log abortions rise 29 percent in regressions for whites and blacks combined; log births are unchanged or rise modestly, which results in a statistically significant increase in the abortion ratio of approximately 16 percent for blacks and whites combined evaluated at the mean (top panel). ${ }^{19}$ The DDDs, however, generally reduce the magnitude of the effect, and none of the estimates are statistically significant, although the standard errors for abortion are rather large. In addition, the cross-state DD for abortion is essentially zero, which combined with the rise in births, causes the abortion ratio to decline. Separate estimates for whites and blacks follow a similar pattern. Results for teens are in the lower third of Table 6 . We show only the cross-state DD for teens since we do not consider teens of zero parity an appropriate comparison group for higher parity teens. ${ }^{20}$ Inferences for teens are similar to those of adults. The increase in abortions is offset by the rise in births leaving the abortion ratio unchanged. From this we infer that trends in birth and abortion rates among women at risk for public assistance differ importantly by parity, but neither the trends nor the differences in the trends appear related to the family cap.

\footnotetext{
${ }^{19}$ The change in the abortion ratio relative to the mean is approximately $.040 / .250$ or 16 percent.

${ }^{20}$ Our conclusions do not change if we use teens of zero parity as a comparison group.
} 
Regression-adjusted estimates for the abortion ratio are very similar to those from the simple DDs and DDDs in Table 5. There is less agreement between the regression results in Table 6 and the simple DD estimates for birth and abortion rates in Tables 3 and 4, especially among teens. DD estimates for adults in Table 3 indicate that birth rates fell between 1992/93 and 1998/99 in family cap states whereas in Table 6 similar changes in log births adjusted for the aggregate population suggest that this proxy for birth rates increased after implementation of the family cap. Otherwise, results pertaining to adults in Tables 3, 4 and 6 are consistent. For teens, the DD estimates in Tables 3 and 4 indicate that birth and abortion rates fell between 1992/3 and 1998/99. But in Table 6, changes in adjusted log births and log abortions imply an increase in births and abortion rates before and after implementation of family cap policies. This disagreement may be related to the different specification of year and policy effects, or to the measurement error associated with population. We suspect that our inability to adequately adjust for population in the log birth regressions is the most plausible explanation. First, the DDs and DDDs for the abortion ratio in Table 5 and the regressionadjusted estimates in Table 6 are almost identical, which suggests that the more refined timing of the policy measures in the regressions does not alter the estimates. Second, we computed simple DDs and DDDs as in Tables 3 and 4 with the natural log of births and abortions as the outcome (results not shown). They were also very similar to the adjusted estimates in Table 6 . In other words, the inclusion of the log of the state population by age and race on the right-hand-side of equation (1) had little effect on our estimates. Third, other researchers have obtained similar results. Kearney (forthcoming), Joyce, Kaestner and Korenman (forthcoming) and Levine (2002) have also found that the family cap is positively related to log births in selected samples of low-educated, unmarried women. The counter-intuitive result is generally statistically insignificant, but the sign and magnitude of the coefficient is similar to the estimates that we report in Table 6 .

The lack of detailed population data for the relevant subgroups by state and year is a key motivation for including the abortion ratio as an outcome. Although we cannot make inferences about changes in pregnancies associated with the family cap with the abortion ratio, it is relatively well-measured among women and teens who are likely exposed to welfare reform. Moreover, the change in the abortion ratio, conditional on pregnancy is relevant for many poor women, and especially teens, given the prevalence of 
unintended pregnancy. In addition, changes in the abortion ratios reflect relative changes in birth and abortion rates. Since the DDDs for the abortion ratios are small and statistically insignificant, and since the simple DDDs of birth and abortion rates are also inconsistent with an effect of the family cap, we conclude that the family cap has not affected decisions regarding pregnancy or how pregnancies are resolved.

\section{Conclusion}

Some of the architects of welfare reform were concerned that reductions in non-marital childbearing might be accompanied by an increase in abortion. An experimental analysis of New Jersey's family cap implemented in 1992 indicated that these fears were well-founded, as births fell and abortions rose in response to the policy change (Jagannathan and Camasso 2003). On the other hand, several non-experimental studies have found no effect of the family cap. In this study we use individual birth and abortion records from 24 states to obtain estimates of the association between implementation of a family cap and changes in birth and abortion rates among women and teens at risk for public assistance. We found that, although birth rates have fallen among teen and adult mothers most affected by the family cap, they also fell among comparable mothers who lived in states without family caps. We observed a similar pattern with abortions: a relative increase among women of higher parity in states with and without a family cap. We speculate that a decline in pregnancy rates at higher parities may be related to welfare reform more generally or other contemporaneous influences, but that these trends are not a specific response to the family cap.

A contribution of our study is the addition of abortions as an outcome. Except for the evaluation of New Jersey's family cap, all previous non-experimental studies have been limited to an analysis of births. Abortion data contribute to our analysis in two ways. First, abortion data can provide confirmatory evidence of a possible association of fertility behaviors with the family cap. Birth rates of teens at higher parities, for instance, fell relatively more in states with compared to states without a family cap. However, the relative decline of abortion rates among teens of higher parity was also greater in states with a family cap, which is inconsistent with an effect of the family cap. A second advantage of data on abortion is that they allow multivariate analysis of the abortion ratio for women of lower economic status. We would have preferred to 
analyze both birth and abortion rates with multivariate methods, but population data are not available in sufficient detail. Importantly, multivariate estimates of the association between the family cap and the abortion ratio were very similar to the simple DDs and consistent with the simple DDs of the birth and abortion rates.

A limitation of the abortion ratio as an outcome is that it provides no information on changes in contraception and sexual activity associated with the family cap. However, unintended pregnancy is quite prevalent among women on public assistance, which suggests that pregnancy resolution (abortion ratios) may be sensitive to changes in fertility intentions (timing or completed fertility). For instance, the abortion rate among women with income less than 100 percent of the federal poverty level is two to three times the abortion rate of women with incomes above 300 percent of poverty (Jones, Darroch and Henshaw 2002). Welfare recipients often report that their births are the result of unintended pregnancies. In an evaluation of Delaware's waiver program, A Better Chance (ABC), 82 percent of the welfare participants that had a baby during the trial reported that the pregnancy was unintended (Fein 1999). In short, the high prevalence of unintended pregnancy among women of lower socioeconomic status leads us to expect that a substantial decline in births associated with the family cap should be accompanied by an increase in the abortion ratio.

A limitation of vital statistics is the inability to precisely identify women on or at risk for public assistance. As a result, we may have had insufficient power to detect small but statistically significant changes in reproductive choices associated with the family cap. The advantage of our approach as opposed to an analysis of women on welfare is that we are able to capture changes among those at risk for public assistance provided the response is sufficiently large to be detected. Our results suggest that there have been no major reproductive responses to the family cap. 


\section{Acknowledgements}

This research was supported by grant R01 HD40834-03 from the National Institute of Child Health and Human Development (NICHD), National Institutes of Health to the National Bureau of Economic Research (NBER). The views expressed herein are those of the authors and not necessarily those of Baruch College, the NBER, NICHD or the Alan Guttmacher Institute. We thank Jeffery Grogger ,participants at the AGI seminar and two anonymous referees for helpful comments . Silvie Colman and Danielle Ferry provided excellent research assistance. All errors are ours. This paper is forthcoming in a special issue of Population Research and Policy Review. 


\section{References}

Acs, G. (1996). The impact of welfare on young mother's subsequent childbearing Decisions. Journal of Human Resources. 31(4): 898-915.

Argys, L. M., Averett, S. L. \& Rees, D. I. (2000). Welfare generosity, pregnancies and abortions among unmarried AFDC recipients. Journal of Population Economics 13:569-594

Bertrand, M., Duflo, E. \& Mullainathan, S. (2002). How much should we trust differences-in-differences estimates? National Bureau of Economic Research, Inc. Working Paper 8841.

Blank, R. (2002). Evaluating welfare reform in the United States. Journal of Economic Literature Vol.XL(4): $1105-1166$.

Blank, R. M., George, C. C., \& London, R. A. (1996). State abortion rates: The impact of policies, providers, politics, demographics, and economic environment. Journal of Health Economics 15, pp. 513-553.

Camasso, M. J., Jagannathan, R., Harvey, C. and M. Killingsworth. (2003). The use of client surveys to gauge the threat of contamination in welfare reform experiments. Journal of Policy Analysis and Management. 22(2):207-223.

Camasso, M. J., Harvey, C., Killingsworth, M., \& Jagannathan, R. (1999). New Jersey's family cap and family size decisions: Some findings from a five-year evaluation. Unpublished manuscript, Rutgers University.

Camasso, M. J., Harvey, C., Jagannathan, R.,and M. Killingsworth (1998a). A final report on the impact of New Jersey's family development Program: results from a pre-post analysis of AFDC case heads from 1990-1996. U.S. Department of Health and Human Services.

Camasso, M. J., Harvey, C., Jagannathan, R.,and M. Killingsworth (1998b). A final report on the impact of New Jersey's family development program. State of New Jersey Department of Human Services.

Center for Disease Control and Prevention. (1999). Vital statistics of the United States: Natality, 1997. Technical Appendix.

Cook, P.J., Parnell, A., Moore, M. and D. Pagnini (1999). The effect of short-term variation in abortion funding on pregnancy outcomes. Journal of Health Economics 18(2):241-258.

Council of Economic Advisors. (1997). Technical Report: Explaining the decline in welfare receipt, 19931996.

Dye, J. L. \& Presser, H. B. (1999). The state bonus to reward a decrease in 'illegitimacy': Flawed methods and questionable effects. Family Planning Perspectives 31(3): 142-147.

Dyer, W. \& Fairlie, R. (2001). Do family caps reduce out-of-wedlock births? Evidence from Arkansas, Georgia, Indiana, New Jersey and Virginia. Manuscript. University of California at Santa Cruz, Department of Economics.

Fairlie, R. W. \& London, R. A. (1997). The effect of incremental benefit levels on births to AFDC recipients. Journal of Policy Analysis and Management 16(4): 575-597. 
Fein, D. J. (1999). Will welfare reform influence marriage and fertility? Evidence from the ABC demonstration. Abt Associates Inc.

Grogger, J. (2002). The behavioral effect of welfare time limits. American Economic Review 92(2):385-389.

Grogger, J. (2003). Welfare transitions in the 1990s: The economy, welfare policy, and the EITC. National Bureau of Economic Research. Working Paper 9472.

Grogger, J. \& Bronars, S. G. (2001). The effect of welfare payments on the marriage and fertility behavior of unwed mothers: Results from a twins experiment. Journal of Political Economy 109(3).

Grogger, J., Karoly, L., \& Klerman, A. (2002). Consequences of welfare reform: A research synthesis (DRU2676-DHHS). RAND: Santa Monica, CA.

Hechman, J. \& Smith, J. (1995). Assessing the case for social experiments. Journal of Economic Perspectives 9(2):85-110.

Henshaw, S. (1998). Unintended pregnancy in the United States. Family Planning Perspectives 30(1):24-29 \& 46.

Henshaw, S. (2000). Birth and abortion data. http://www.welfareacademy.org/pubs/dataneeds/dataneedshenshaw.pdf

Henshaw, S. \& Kost, K. (1996). Abortion Patients in 1994-1995: Characteristics and contraceptive use. Family Planning Perspectives 28(4):140-147.

Horvath-Rose, A. E. \& Peters, E. H. (2001). Welfare waivers and nonmarital childbearing. For better and worse. Welfare Reform and the Well-Being of Children and Families. Russell Sage Foundation, New York

Jagannathan, R. \& Camasso, M. J. Forthcoming. (2003). Family Cap and Nonmarital Fertility: The Racial Conditioning of Policy Effects. Journal of Marriage and the Family 65(1):52-71.

Jagannathan, R., Camasso, M. J., \& Killingsworth, M. Forthcoming. New Jersey's Family Cap Experiment: Do Fertility Impacts Differ by Racial Density? Journal of Labor Economics.

Jones, R. K., Darroch, J. E. \& Henshaw, S. (2002). Patterns in the socioeconomic characteristics of women obtaining abortions in 2000-2001. Perspectives on Sexual and Reproductive Health 34(5): 226-235.

Joyce, T, Kaestner, R. \& Korenman, S. (2002). Welfare reform and non-marital fertility in the 1990s: evidence from birth records. National Bureau of Economic Research, Inc. Working Paper 9406.

Joyce, T., Kaestner, R., Korenman, S. \& Henshaw, S. (2003). Changes in births and abortions following welfare reform. Presented at the annual meeting of Population Association of American, Minneapolis, MN, May 1, 2003.

Kaushal, N. \& Kaestner, R. (2001). From welfare to work: Has welfare reform worked? Journal of Policy Analysis and Management 20(4):699-719.

Kearney, M. Forthcoming. Is there an effect of incremental welfare benefits on fertility behavior? A look at the family cap. Journal of Human Resources. 
Klerman, J. (1998). Welfare reform and abortion. In Robert Moffitt, editor, Welfare, The family, and reproductive behavior: Research perspectives. Washington, DC : National Academy Press. p. 97-133.

Koonin L. M. et al. (1999). Abortion surveillance--United States, 1996. In: CDC surveillance summaries (July 30). MMWR 48(No. SS4).

Levine, P. (2002). The impact of social policy and economic activity throughout the fertility decision tree. National Bureau of Economic Research Working Paper 9021.

Levine, P. \& Staiger, D. (2002). Abortion as insurance. National Bureau of Economic Research Working Paper 8813.

Loury, G. (2000). Preventing subsequent births to welfare recipients. http://www.welfareacademy.org/eval/loury.html

Lundberg, S. \& Plotnick, R. (1995). Adolescent premarital childbearing: Do economic incentives matter? Journal of Labor Economics 13:177-201.

Mach, T. (2001). Measuring the impact of family caps on childbearing decisions. Manuscript. State University of New York at Albany, Department of Economics.

Matthews, S. et al. (1997). The effects of economic conditions and access to reproductive health services on state abortion rates and birthrates. Family Planning Perspectives 29(2), 52-60.

Mills, G., Kornfeld, R., Porcari, D. and D. Laliberty (2001). Evaluation of the Arizona EMPOWER Welfare Reform Demonstration. Final Report to the Arizona Department of Economic Security. Abt Associates Inc.

Moffitt, R. A. (1998). The effect of welfare on marriage and fertility. In Robert Moffitt, editor, Welfare, The Family, and Reproductive Behavior: Research Perspectives. Washington, DC : National Academy Press. p. 50-97.

Moffitt, R. A. (2003a). The temporary assistance for needy families program. In Robert A. Moffitt editor. Means-tested Transfer Programs in the United States. Chicago: NBER/Chicago University Press. Pp.

Moffitt, R.A. (2003b). The role of randomized field trials in social science research: A perspective from evaluations of reforms of social welfare programs. DP 1264-03, IRP, University of Wisconsin. June.

New York City Department of Health. (1999). Summary of Vital Statistics 1998: The City of New York.

O'Neill, J. E., \& Hill, M. A. (2001). Gaining ground? Measuring the impact of welfare reform on welfare and work. The Manhattan Institute. No. 17.

Rector, R. \& Youssef, S. (1999). The determinants of welfare caseload decline. Center for Data Analysis Report \#99-04. Washington, D.C: Heritage Foundation.

Rossi, P. (2000). New Jersey's family development program: An overview and critique of the rutgers evaluation. http://www.welfareacademy.org/eval/toc.cfm 
Schoeni, R. F. \& Blank, R. M. (2000). What has welfare reform accomplished? Impacts on welfare participation, employment, income, poverty and family structure. NBER Working Paper 7627, March.

Ventura, S. J. \& Bachrach, Ch.A. (2000). Nonmarital childbearing in the United States, 1940-99. National Vital Statistics Report, Centers for Disease Control and Prevention. 
Table 1.

Total Abortions by State of Occurrence as Reported by the Alan Guttmacher Institute and State Health Departments, 1996

\begin{tabular}{|c|c|c|c|}
\hline State: & AGI & State Health Department & Percent Difference \\
\hline Alabama & 15150 & 13826 & -8.7 \\
\hline Arizona & 19310 & 11016 & -43.0 \\
\hline Arkansas & 6200 & 5882 & -5.1 \\
\hline Hawaii & 6930 & 4916 & -29.1 \\
\hline Idaho & 1600 & 1022 & -36.1 \\
\hline Kansas & 10630 & 10683 & 0.5 \\
\hline Maine & 2700 & 2602 & -3.6 \\
\hline Minnesota & 14660 & 14193 & -3.2 \\
\hline Mississippi & 4490 & 4206 & -6.3 \\
\hline Missouri & 10810 & 11629 & 7.6 \\
\hline Montana & 2900 & 2763 & -4.7 \\
\hline Nevada & 15450 & 6965 & -54.9 \\
\hline New York* & 167600 & 145519 & -13.2 \\
\hline North Carolina & 33550 & 33554 & 0.0 \\
\hline North Dakota & 1290 & 1292 & 0.2 \\
\hline Ohio & 42870 & 36426 & -15.0 \\
\hline Oregon & 15050 & 13767 & -8.5 \\
\hline Rhode Island & 5420 & 5432 & 0.2 \\
\hline South Carolina & 9940 & 9326 & -6.2 \\
\hline Tennessee & 17990 & 16153 & -10.2 \\
\hline Texas & 91270 & 91470 & 0.2 \\
\hline Utah & 3700 & 3637 & -1.7 \\
\hline Virginia & 29940 & 25770 & -13.9 \\
\hline West Virginia & 2610 & 2470 & -5.4 \\
\hline
\end{tabular}

* includes NYC 
Table 2.

Total Abortions and Percent with Missing data by Characteristics of Women in 26 States, 1992-2000

\begin{tabular}{|c|c|c|c|c|c|c|c|c|}
\hline \multirow[b]{2}{*}{ State of Occurrence } & \multirow[b]{2}{*}{$\begin{array}{c}\text { Number of Total } \\
\text { Abortions } \\
\end{array}$} & \multicolumn{5}{|c|}{ \% Unknown in Following Fields: } & \multirow[b]{2}{*}{$\begin{array}{c}\text { \% of Total } \\
\text { Lost } \\
\end{array}$} & \multirow[b]{2}{*}{$\begin{array}{c}\text { Number of Abortions } \\
\text { Remaining }\end{array}$} \\
\hline & & Education & Age & Race & $\begin{array}{c}\text { Marital } \\
\text { Status } \\
\end{array}$ & Parity & & \\
\hline Alabama & 123,999 & 12.04 & 1.32 & 1.05 & 1.51 & 0.93 & 15.44 & 104,848 \\
\hline Arizona & 111,722 & 29.65 & 6.01 & 0.00 & 28.87 & 0.00 & $6.01^{\mathrm{a}}$ & 105,012 \\
\hline Arkansas & 51,458 & 5.53 & 2.06 & 1.15 & 2.76 & 4.85 & 14.47 & 44,012 \\
\hline Hawaii & 45,047 & 25.58 & 0.90 & 8.83 & 100.00 & 1.45 & $10.82^{\mathrm{a}}$ & 40,172 \\
\hline Idaho & 9,197 & 4.13 & 0.83 & 0.33 & 0.18 & 0.12 & 5.23 & 8,716 \\
\hline Kansas & 100,643 & 0.88 & 1.16 & 0.69 & 0.30 & 0.31 & 3.04 & 97,579 \\
\hline Maine & 24,951 & 8.48 & 1.63 & 2.73 & 12.85 & 10.12 & 29.73 & 17,532 \\
\hline Minnesota & 129,591 & 80.93 & 1.35 & 1.94 & 2.96 & 0.10 & $5.72^{\mathrm{b}}$ & 122,176 \\
\hline Mississippi & 41,221 & 14.67 & 1.54 & 0.16 & 0.36 & 0.06 & 16.25 & 34,522 \\
\hline Missouri & 95,929 & 2.67 & 1.06 & 0.40 & 1.34 & 0.06 & 5.25 & 90,893 \\
\hline Montana & 24,034 & 10.14 & 0.77 & 7.23 & 7.49 & 0.05 & 15.22 & 20,377 \\
\hline Nevada & 60,825 & 4.68 & 2.63 & 12.14 & 3.15 & 0.65 & 17.80 & 49,999 \\
\hline Upstate New York & 376,553 & 24.53 & 1.24 & 15.48 & 100.00 & 2.26 & $29.24^{c}$ & 266,455 \\
\hline New York City & 933,324 & 8.49 & 1.08 & 4.34 & 2.81 & 0.87 & 15.35 & 790,089 \\
\hline North Carolina & 295,645 & 20.34 & 3.19 & 2.17 & 10.82 & 1.86 & 25.81 & 219,350 \\
\hline North Dakota & 11,971 & 1.54 & 0.58 & 0.17 & 0.40 & 0.04 & 2.53 & 11,668 \\
\hline Ohio & 328,735 & 5.37 & 1.64 & 6.52 & 3.24 & 11.45 & 23.41 & 251,765 \\
\hline Oregon & 124,179 & 2.65 & 1.26 & 1.48 & 3.66 & 0.80 & 7.45 & 114,932 \\
\hline Rhode Island & 50,982 & 15.99 & 0.58 & 1.88 & 7.18 & 0.02 & 18.58 & 41,508 \\
\hline South Carolina & 86,078 & 0.21 & 0.98 & 0.02 & 0.04 & 0.02 & 1.25 & 85,006 \\
\hline Tennessee & 146,702 & 22.65 & 0.22 & 0.49 & 0.69 & 0.28 & $1.56^{\mathrm{b}}$ & 144,420 \\
\hline Texas & 773,334 & 100.00 & 1.46 & 4.12 & 5.11 & 0.26 & $9.01^{b}$ & 703,644 \\
\hline Utah & 32,624 & 1.23 & 1.01 & 4.98 & 0.36 & 0.13 & 7.14 & 30,294 \\
\hline Virginia & 242,924 & 13.10 & 1.16 & 1.49 & 12.58 & 1.68 & 22.05 & 189,371 \\
\hline West Virginia $\$$ & 23,221 & 4.48 & 0.91 & 0.08 & 0.24 & 0.07 & 5.54 & 21,935 \\
\hline *Total (18 states + NYC): & $2,661,940$ & 8.91 & 1.46 & 3.36 & 4.50 & 2.38 & 16.44 & $2,224,396$ \\
\hline Total (24 states): & $4,244,889$ & 10.85 & 1.51 & 4.40 & 4.42 & 1.77 & $7.31 * *$ & $3,934,536$ \\
\hline
\end{tabular}

* Excluded states: AZ, HI, MN, NY, TN, TX. **\% lost based on age, race and parity.

${ }^{\mathrm{a}}$ not including education and marital status; ${ }^{\mathrm{b}}$ not including education; ${ }^{\mathrm{c}}$ not including marital status.

\$ 1993 is missing for Indiana and 1992 for West Virginia. We use 1992 abortion for 1993 in Indiana and 1993 for 1992 abortion in West Virginia to create balanced panels. 
Table 3.

Birth Rates for Teens and Unmarried Women Ages 20-34 with 12 or Fewer Years of Schooling by Year of Conception. Race and States with and without Familv Caps, 1992-1999*

\begin{tabular}{ccccccc}
\hline & \multicolumn{2}{c}{ First Difference } & \multicolumn{2}{c}{ Difference-in-differences } \\
\cline { 2 - 6 } & $\mathbf{1 9 9 2 - 1 9 9 3}$ & $\mathbf{1 9 9 8 - 1 9 9 9}$ & Absolute & Relative & Absolute & Relative \\
$(1)$ & $(2)$ & $(3)$ & $(4)$ & $(5)$ & $(6)$ \\
\hline
\end{tabular}

TEENS:

States with a Family Cap Provision:

$\begin{array}{lcccc}\text { All parities } & 67 & 61 & -6 & -0.103 \\ \text { Parity: } 1+ & 202 & 114 & -88 & -0.572\end{array}$

States without a Family Cap Provision:

$\begin{array}{lcccccc}\text { All parities } & 64 & 45 & -14 & -0.271 & & \\ \text { Parity: } 1+ & 162 & 109 & -53 & -0.396 & -35 & -0.176\end{array}$

ADULTS:

States with a Family Cap Provision:

\begin{tabular}{|c|c|c|c|c|c|}
\hline All parities & 112 & 107 & -5 & -0.050 & \\
\hline Parity: 0 & 91 & 92 & 1 & 0.012 & \\
\hline Parity: $1+$ & 126 & 116 & -11 & -0.090 & -12 \\
\hline
\end{tabular}

States without a Family Cap Provision:

\begin{tabular}{|c|c|c|c|c|c|}
\hline All parities & 101 & 104 & 3 & 0.027 & \\
\hline Parity: 0 & 77 & 85 & 8 & 0.096 & \\
\hline Parity: 1+ & 119 & 116 & -2 & -0.021 & -10 \\
\hline
\end{tabular}

*The teen birth rate is defined as births per 1000 teens of designated parity. The adult birth rate is births per 1000 unmarried women with 12 or fewer years of schooling of the indicated parity. Population estimates are from the June CPS Fertility Module in 1992, 1994, 1998 and 2000. We use population estimates in 1992 and 1994 for the years 1992-93 and the June CPS in 1998 and 2000 for the years 1998-99. The adult sample includes 18 states: AL, AR, ID, KS, ME, MS, MO, MT, NV, NC, ND, OH, OR, RI, SC, UT, VA, and WV. The teen sample includes 6 additional states: AZ, HI, MN, NY, TN and TX. Family caps were enforced in Arizona (11/95), Arkansas (7/94), Idaho (7/97), Mississippi (10/95), North Carolina (7/96), North Dakota (7/97), South Carolina (10/96), Tennessee (9/96), and Virginia (7/95). Relative changes are approximated by the difference in logs. The difference-indifferences (DDs) for teens is the change in birth rates among teens of parity one or more in states without family caps subtracted from the change among teens in states with family caps. The DDs for adults within family cap states between women of zero parity and women of higher parity. The DDs in non-cap states are the same. 
Table 4.

Abortion Rates for Teens and Unmarried Women Ages 20-34 with 12 or Fewer Years of Schooling by Year of Conception, Race and States with and without Family Caps,

1992-1999*

\begin{tabular}{|c|c|c|c|c|c|}
\hline \multirow[b]{2}{*}{$\begin{array}{c}1992-1993 \\
(1)\end{array}$} & \multirow[b]{2}{*}{$\begin{array}{c}\text { 1998-1999 } \\
(2)\end{array}$} & \multicolumn{2}{|c|}{ First Difference } & \multicolumn{2}{|c|}{ Difference-in-differences } \\
\hline & & $\begin{array}{c}\text { Absolute } \\
\text { (3) }\end{array}$ & $\begin{array}{c}\text { Relative } \\
\text { (4) }\end{array}$ & $\begin{array}{c}\text { Absolute } \\
\text { (5) }\end{array}$ & $\begin{array}{c}\text { Relative } \\
(6)\end{array}$ \\
\hline
\end{tabular}

TEENS:

States with a Family Cap Provision:

$\begin{array}{lllll}\text { All parities } & 22 & 15 & -7 & -0.354 \\ \text { Parity: } 1+ & 47 & 27 & -21 & -0.569\end{array}$

States without a Family Cap Provision:

$\begin{array}{lllllll}\text { All parities } & 27 & 19 & -7 & -0.369 & & \\ \text { Parity: } 1+ & 65 & 44 & -22 & -0.404 & 1 & -0.165\end{array}$

ADULTS:

States with a Family Cap Provision:

$\begin{array}{lllllll}\text { All parities } & 43 & 32 & -11 & -0.298 & & \\ \text { Parity: } 0 & 38 & 23 & -15 & -0.505 & \\ \text { Parity: } 1+ & 47 & 37 & -9 & -0.220 & 6 & 0.286\end{array}$

States without a Family Cap Provision:

$\begin{array}{lllllll}\text { All parities } & 38 & 40 & 2 & 0.040 & & \\ \text { Parity: } 0 & 28 & 24 & -4 & -0.158 & & \\ \text { Parity: } 1+ & 46 & 50 & 5 & 0.095 & 9 & 0.253\end{array}$

The abortion rate is defined as abortions per 1000 women or teens of the relevant demographic groups. See notes to Table 3 . 
Table 5.

Abortion Ratio for White and Black Teens and Unmarried Women Ages 20-34 with 12 or Fewer Years of Schooling by Year of Conception, and States with and without Family Caps, 1992-1999*

\begin{tabular}{ccccccc}
\hline & \multicolumn{2}{c}{ First Differences } & \multicolumn{2}{c}{ Difference-in-difference } \\
\cline { 2 - 7 } & $\mathbf{1 9 9 2 - 1 9 9 3}$ & $\mathbf{1 9 9 8 - 1 9 9 9}$ & Absolute & Relative & Absolute & Relative \\
$(1)$ & $(2)$ & $(3)$ & $(4)$ & $(5)$ & $(6)$ \\
\hline
\end{tabular}

TEENS:
All parities
0.243
0.2
$-0.043$
$-0.195$
Parity: $1+$
0.19
0.19
0.001
0.003

States without a Family Cap Provision:
All parities
0.295
0.275
$-0.019$
$-0.068$
Parity: $1+$
0.287
0.285
$-0.002$
$-0.005$
0.003
0.008

\section{ADULTS:}
All parities
0.279
0.231
$-0.047$
$-0.186$
Parity: 0
0.296
0.201
$-0.096$
$-0.390$
Parity: $1+$
0.270
0.245
$-0.025$
$-0.097$
0.071
0.293

States without a Family Cap Provision:
All parities
0.275
0.278
0.003
0.009
Parity: 0
0.267
0.221
$-0.047$
$-0.193$
Parity: $1+$
0.279
0.302
0.024
0.082
0.071
0.274 
Table 6.

Adjusted Difference-in-differences (DD) Associated with the Family Cap for the Log of Abortions, the Log of Births, and the Ratio of Abortions to Pregnancies (Abortions plus Births) to Teens and Unmarried Adult Women with 12 or Fewer Years of Schooling by Years of Conception, 1992-1999

\begin{tabular}{|c|c|c|c|c|c|c|c|c|c|}
\hline & \multicolumn{3}{|c|}{ Whites and Blacks: } & \multicolumn{3}{|c|}{ Whites: } & \multicolumn{3}{|c|}{ Blacks: } \\
\hline & $\underset{\text { abortions }}{\operatorname{Ln}}$ & $\begin{array}{c}\text { Ln } \\
\text { births }\end{array}$ & $\mathbf{A} /(\mathbf{A}+\mathbf{B})$ & $\begin{array}{c}\text { Ln } \\
\text { abortions }\end{array}$ & $\begin{array}{c}\text { Ln } \\
\text { births }\end{array}$ & $\mathbf{A} /(\mathbf{A}+\mathbf{B})$ & $\begin{array}{c}\text { Ln } \\
\text { abortions }\end{array}$ & $\underset{\text { births }}{\text { Ln }}$ & $\mathbf{A} /(\mathbf{A}+\mathbf{B})$ \\
\hline & (1) & (2) & (3) & (4) & (5) & (6) & (7) & (8) & (9) \\
\hline \multicolumn{10}{|l|}{ ADULTS: } \\
\hline $\mathrm{DD}_{\text {cap }}$ & $\begin{array}{c}0.294 \\
(0.029)^{* *}\end{array}$ & $\begin{array}{c}0.048 \\
(0.014)^{* *}\end{array}$ & $\begin{array}{c}0.043 \\
(0.012)^{* *}\end{array}$ & $\begin{array}{c}0.245 \\
(0.030)^{* *}\end{array}$ & $\begin{array}{c}0.086 \\
(0.023)^{* *}\end{array}$ & $\begin{array}{c}0.030 \\
(0.010)^{* *}\end{array}$ & $\begin{array}{c}0.269 \\
(0.035)^{* *}\end{array}$ & $\begin{array}{c}0.064 \\
(0.018)^{* *}\end{array}$ & $\begin{array}{c}0.033 \\
(0.012)^{*}\end{array}$ \\
\hline DDD & $\begin{array}{c}0.145 \\
(0.078)^{*}\end{array}$ & $\begin{array}{c}0.055 \\
(0.032)\end{array}$ & $\begin{array}{c}0.012 \\
(0.015)\end{array}$ & $\begin{array}{c}0.080 \\
(0.063)\end{array}$ & $\begin{array}{c}0.030 \\
(0.030)\end{array}$ & $\begin{array}{c}0.008 \\
(0.015)\end{array}$ & $\begin{array}{c}0.083 \\
(0.077)\end{array}$ & $\begin{array}{c}0.077 \\
(0.055)\end{array}$ & $\begin{array}{l}-0.010 \\
(0.013)\end{array}$ \\
\hline $\mathrm{DD}_{\text {cross-state }}$ & $\begin{array}{c}0.002 \\
(0.122)\end{array}$ & $\begin{array}{c}0.073 \\
(0.027)^{* *}\end{array}$ & $\begin{array}{l}-0.025 \\
(0.028)\end{array}$ & $\begin{array}{c}-0.081 \\
(0.136)\end{array}$ & $\begin{array}{c}0.150 \\
(0.064)^{*}\end{array}$ & $\begin{array}{c}-0.051 \\
(0.025)^{*}\end{array}$ & $\begin{array}{c}-0.005 \\
(0.133)\end{array}$ & $\begin{array}{c}0.097 \\
(0.030)^{* *}\end{array}$ & $\begin{array}{l}-0.030 \\
(0.030)\end{array}$ \\
\hline R-squared & 0.958 & 0.989 & 0.753 & 0.952 & 0.991 & 0.733 & 0.962 & 0.992 & 0.858 \\
\hline $\mathrm{N}$ & 288 & 288 & 288 & 288 & 288 & 288 & 216 & 216 & 216 \\
\hline \multicolumn{10}{|l|}{ TEENS: } \\
\hline $\mathrm{DD}_{\text {cross-state }}$ & $\begin{array}{c}0.113 \\
(0.077)\end{array}$ & $\begin{array}{c}0.062 \\
(0.029)^{\text {** }}\end{array}$ & $\begin{array}{c}0.012 \\
(0.014)\end{array}$ & $\begin{array}{c}0.069 \\
(0.069)\end{array}$ & $\begin{array}{c}0.069 \\
(0.037)\end{array}$ & $\begin{array}{c}0.001 \\
(0.010)\end{array}$ & $\begin{array}{c}0.115 \\
(0.086)\end{array}$ & $\begin{array}{c}0.077 \\
(0.033)\end{array}$ & $\begin{array}{c}0.007 \\
(0.019)\end{array}$ \\
\hline R-squared & 0.986 & 0.994 & 0.941 & 0.986 & 0.995 & 0.938 & 0.981 & 0.985 & 0.949 \\
\hline $\mathrm{N}$ & 384 & 384 & 384 & 384 & 384 & 384 & 304 & 304 & 304 \\
\hline
\end{tabular}

Note: DD cap refers to difference-in-differences within family cap states. The DDD subtracts the DD in non-cap states from the DD in cap states. The DD cross-states refers to difference-in-differences among births of parity 1 or higher between cap and non-cap states. All regressions include state and year fixed effects. Standard errors have been corrected for clustering within states. ${ }^{+}$significant at $10 \%$; ${ }^{*}$ significant at $5 \%{ }^{* *}$ significant at $1 \%$ 
Figure 1. Abortions per 1000 women of ages 15-44 nationally and for selected states by source,

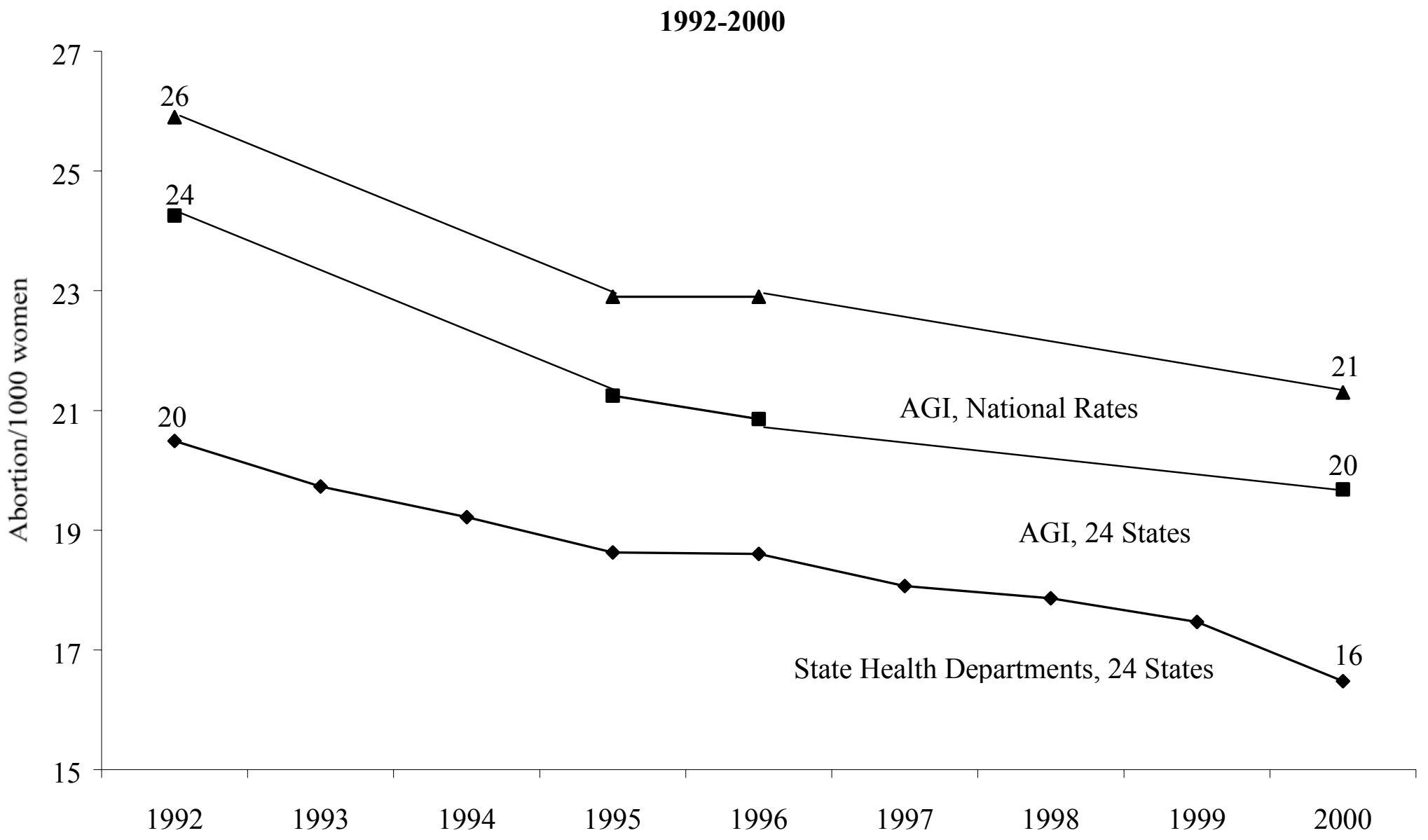


Figure 2. Abortion and birth rates for white and black unmarried, low-ed women aged 20-34, in 18 states*, by years of conception, 1992-99

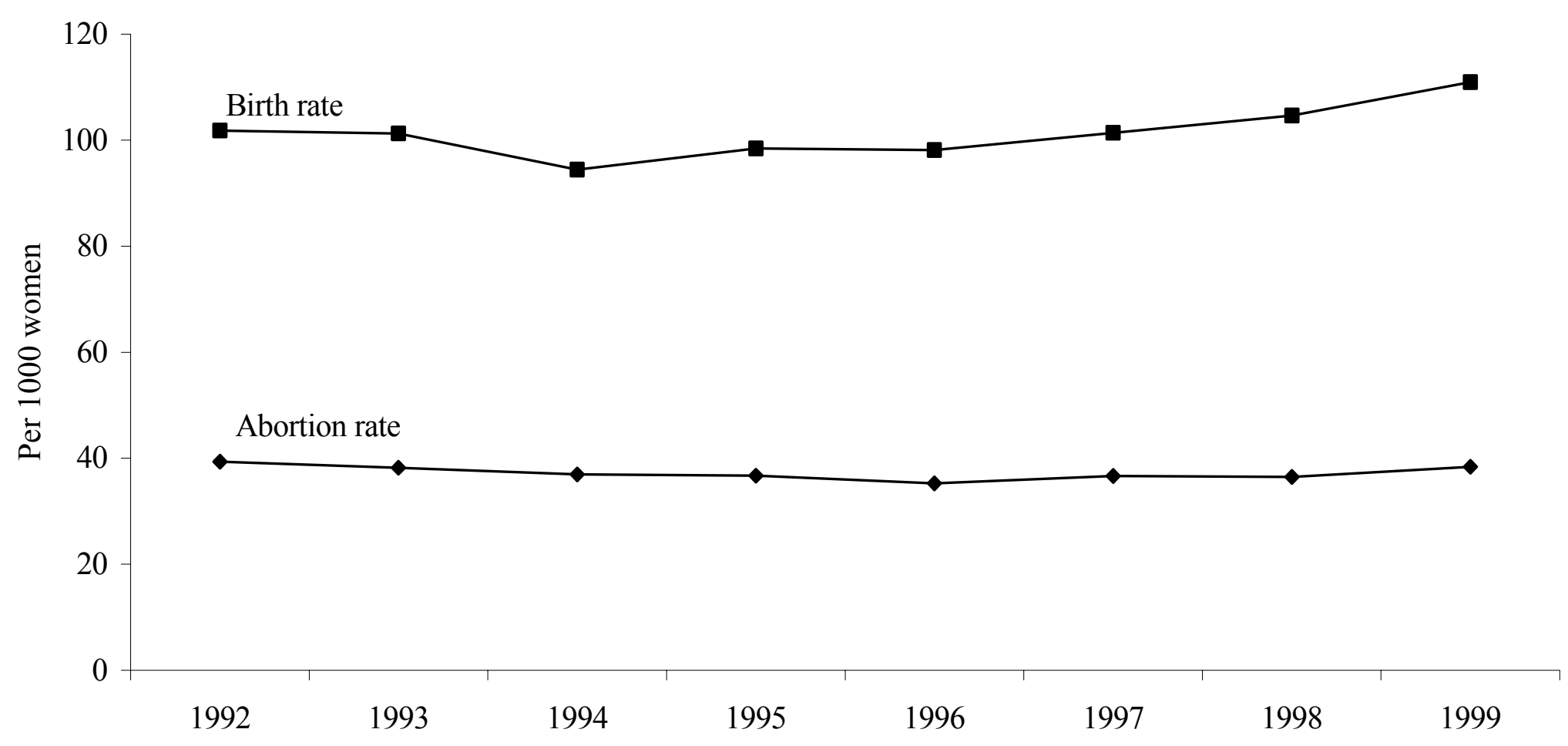

* AL, AR, ID, KS, ME, MS, MO, MT, NV, NC, ND, OH, OR, RI, SC, UT, VA, WV.

Population estimates are from the CPS Outgoing Rotation Files. 
Figure 3. Abortion and birth rates for white and black teens aged 15-19 in 24 states*, by family cap state and years of conception, 1992-1999

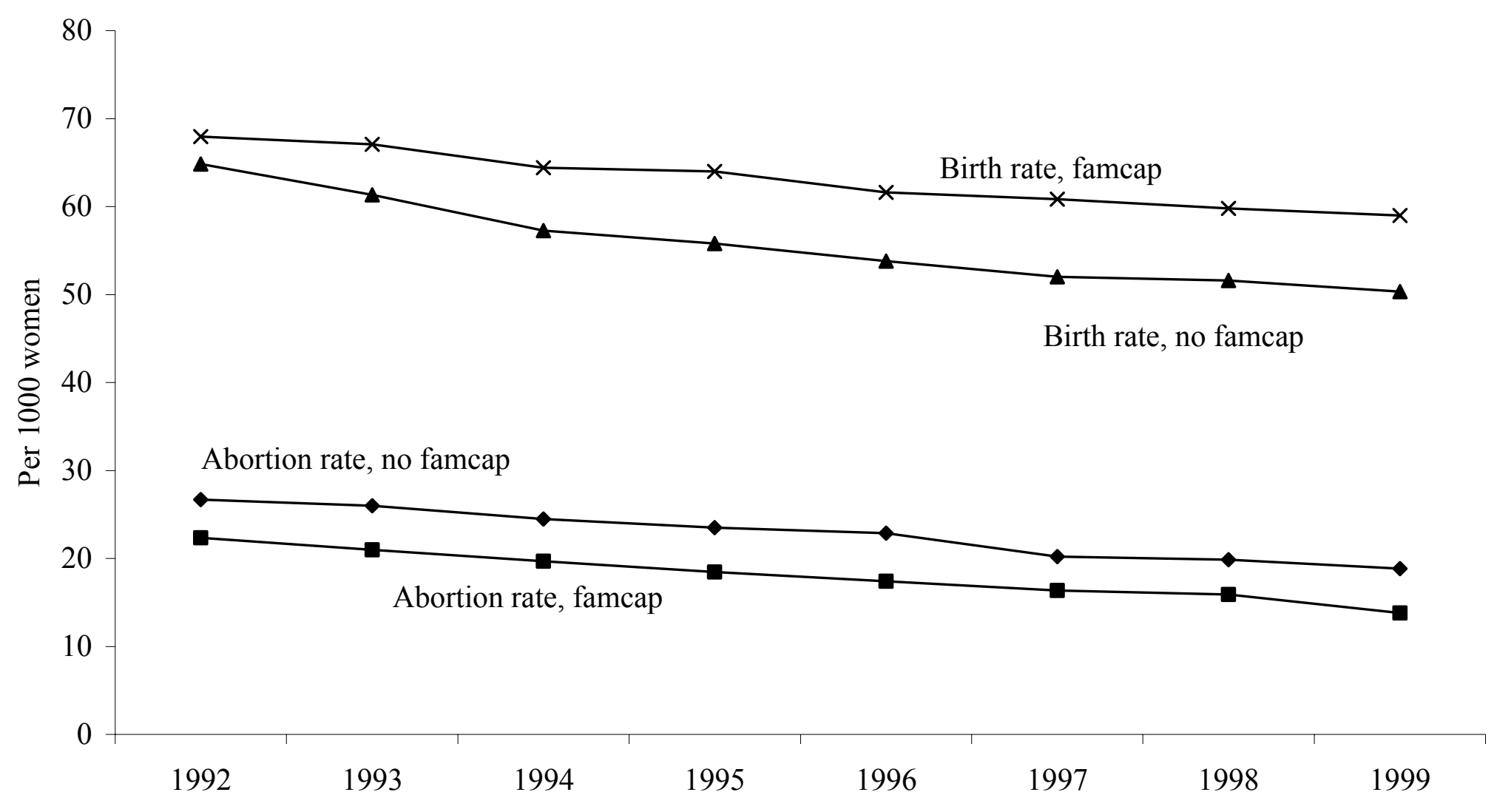

* AL, AZ, AR, HI, ID, KS, ME, MN, MS, MO, MT, NV,NY, NC, ND, OH, OR, RI, SC, TN, TX, UT, VA, WV. Population estimates are from the U.S. Census Bureau. 
Appendix Table 1.

Availability of Micro-level Induced Termination of Pregnancy Files, 1992-2000

States that Contributed Data -- Maternal Characteristics and Years Available:

Non-Contributing States - Reasons:

\begin{tabular}{llll}
\hline $\begin{array}{l}\text { Abortions by age, race, } \\
\text { marital status, parity } \\
\text { schooling, 1992-2000 }\end{array}$ & $\begin{array}{l}\text { Abortions by age and race but } \\
\text { missing marital status (m) or } \\
\text { schooling (ed), parity or years }\end{array}$ & $\begin{array}{l}\text { Abortions by age but missing race } \\
(\boldsymbol{r}) \text { or marital status (ms) or } \\
\text { schooling (ed) or years (1992-00) }\end{array}$ & $\begin{array}{l}\text { Abortions unavailable due to statutory } \\
\text { restrictions (sr) or inadequate data } \\
\text { collection and or storage (idc) }\end{array}$ \\
\hline Alabama & Arizona (only 2 categories of ed) & Delaware (92-96) & Alaska (idc) \\
Arkansas & Colorado (parity) & Georgia (92-93, 00) & California (idc) \\
Idaho & Indiana (parity) & Michigan (ed, r, 92-95) & Connecticut (idc) \\
Kansas & Hawaii (ms) & Oklahoma (92-99) & Florida (idc) \\
Maine & New Jersey (ed, select counties) & & Illinois (sr) \\
Mississippi & New York (excluding NYC) (ms) & & Iowa (sr) \\
Missouri & Tennessee (1999-2000, ed) & Kentucky (idc) \\
Montana & Texas (ed) & & Louisiana (sr) \\
Nevada & Minnesota (ed, 92-98) & Maryland (idc) \\
New York City & & & Massachusetts (idc) \\
North Carolina & & & Nebraska (idc) \\
North Dakota & & New Hampshire (idc) \\
Ohio & & New Mexico (idc) \\
Oregon & & Pennsylvania (sr) \\
Rhode Island & & South Dakota (sr) \\
South Carolina & & Vermont (sr) \\
Utah & & & Washington (idc) \\
Virginia & & Washington D.C. (idc) \\
West Virginia (1992) & & Wisconsin (sr) \\
& & & Wyoming (sr) \\
\hline
\end{tabular}




\section{Appendix Table 2.}

Proportion of Women 20 to 34 years of Age Whose Birth or Abortion Was Financed by Medicaid in 1994 By Education, Marital Status and Parity

\section{Demographic Group:}

Percent of abortions to Women on Medicaid *
Percent of Births to Women on Medicaid **

\section{No previous live births:}

Less than 12 years of schooling - Not Married 12 years of schooling-Not Married

12 or more years of schooling-Not Married

12 or more years of schooling--Married

$\begin{array}{cc}25.2 \%(103) & 85.2 \\ 21.8 \%(441) & 71.8 \\ 10.2 \%(1631) & 58.9 \\ 8.9 \%(180) & 17.9\end{array}$

$42.0 \%(500)$

93.1

$36.5 \%(1296) \quad 80.6$

$24.2 \%(1583) \quad 67.8$

$14.3 \%(792) \quad 20.8$

* Authors' tabulations of 1994 survey of abortion patients (Henshaw and 1996). Only states that finance abortions for women on Medicaid are included.

**1994 10 States in PRAMS 
Table A3.

Pregnancy Rates for Teens and Unmarried Women Ages 20-34 with 12 or Fewer Years of Schooling by Year of Conception, Race and States with and without Family Caps, 1992-1999*

\begin{tabular}{|c|c|c|c|c|c|c|}
\hline \multirow{3}{*}{ TEENS: } & \multirow[b]{2}{*}{$\begin{array}{c}\text { 1992-1993 } \\
\text { (1) }\end{array}$} & \multirow[b]{2}{*}{$\begin{array}{c}\text { 1998-1999 } \\
\text { (2) }\end{array}$} & \multicolumn{2}{|c|}{ First Difference } & \multicolumn{2}{|c|}{ Difference-in-differences } \\
\hline & & & $\begin{array}{c}\text { Absolute } \\
\text { (3) }\end{array}$ & $\begin{array}{c}\text { Relative } \\
\text { (4) }\end{array}$ & $\begin{array}{c}\text { Absolute } \\
\text { (5) }\end{array}$ & $\begin{array}{c}\text { Relative } \\
\text { (6) }\end{array}$ \\
\hline & \multicolumn{3}{|c|}{ States with a Family Cap Provision } & & & \\
\hline All parities & 89 & 76 & -13 & -0.159 & & \\
\hline Parity: 0 & 75 & 67 & -8 & -0.112 & & \\
\hline \multirow[t]{2}{*}{ Parity: 1+ } & 249 & 141 & -109 & -0.572 & & \\
\hline & \multicolumn{4}{|c|}{ States without a Family Cap Provision } & & \\
\hline All parities & 91 & 67 & -24 & -0.302 & & \\
\hline Parity: 0 & 77 & 58 & -19 & -0.285 & & \\
\hline Parity: $1+$ & 228 & 153 & -75 & -0.398 & -34 & -0.173 \\
\hline \multicolumn{7}{|l|}{ ADULTS: } \\
\hline & \multicolumn{3}{|c|}{ States with a Family Cap Provision } & & & \\
\hline All parities & 156 & 139 & -17 & -0.113 & & \\
\hline Parity: 0 & 129 & 115 & -14 & -0.116 & & \\
\hline \multirow[t]{2}{*}{ Parity: 1+ } & 173 & 153 & -20 & -0.123 & -6 & -0.007 \\
\hline & \multicolumn{4}{|c|}{ States without a Family Cap Provision } & & \\
\hline All parities & 139 & 143 & 4 & 0.031 & & \\
\hline Parity: 0 & 105 & 109 & 4 & 0.034 & & \\
\hline Parity: $1+$ & 164 & 167 & 2 & 0.013 & -2 & -0.021 \\
\hline
\end{tabular}

*The teen pregnancy rate is defined as pregnancies per 1000 teens of designated parity. The adult pregnancy rate is pregnancies per 1000 unmarried women with 12 or fewer years of schooling of the indicated parity. Population estimates are from the June CPS Fertility Module in 1992, 1994, 1998 and 2000. We use population estimates in 1992 and 1994 for the years 1992-93 and the June CPS in 1998 and 2000 for the years 1998-99. The adult sample includes 18 states: AL, AR, ID, KS, ME, MS, MO, MT, NV, NC, ND, OH, OR, RI, SC, UT, VA, and WV. The teen sample includes 6 additional states: AZ, HI, MN, NY, TN and TX. Family caps were enforced in Arizona (11/95), Arkansas (7/94), Idaho (7/97), Mississippi (10/95), North Carolina (7/96), North Dakota (7/97), South Carolina (10/96),

Tennessee (9/96), and Virginia (7/95). Relative changes are approximated by the difference in logs. The difference-in-differences (DDs) for teens is the change in pregnancy rates among teens of parity one or more in states with and without family caps. 
Figure A1. Abortion and birth rates for unmarried, low-ed women aged 20-34 by race, 18 states* and years of conception, 1992-1999

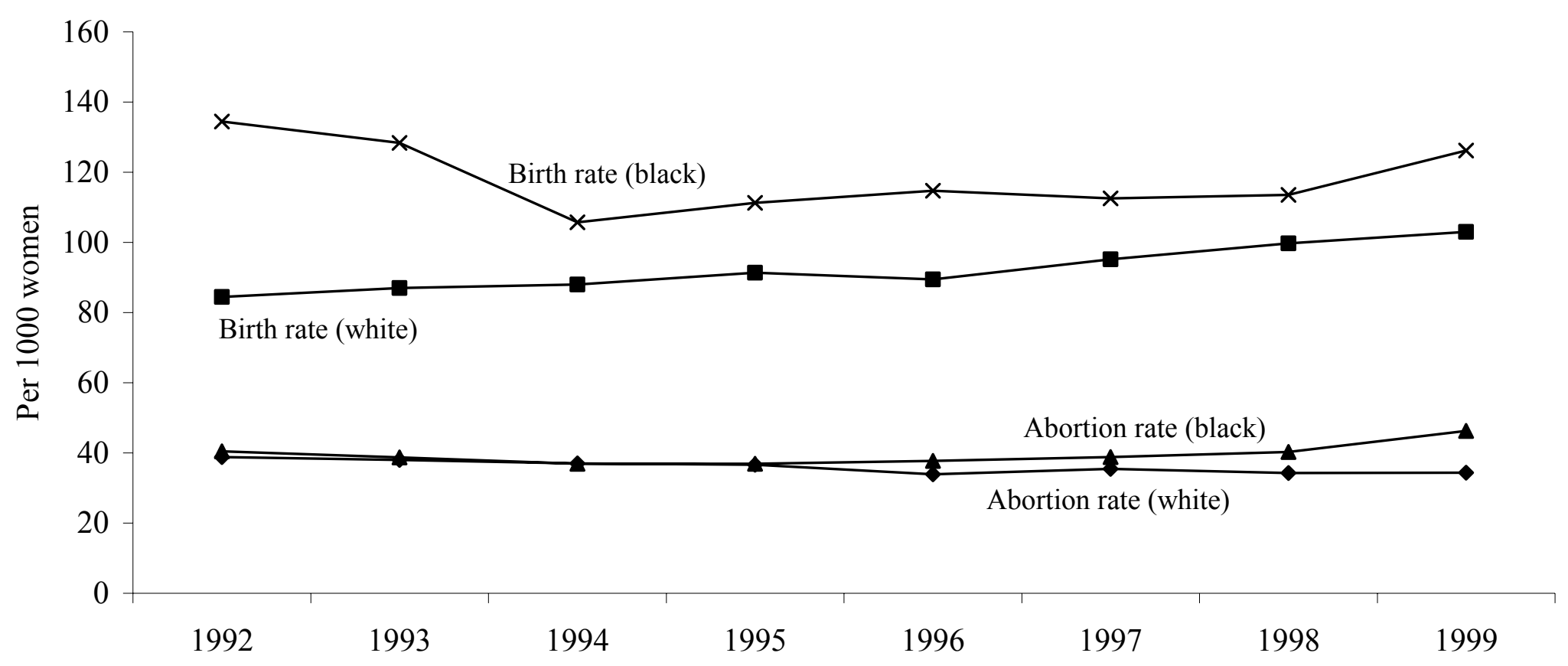

* AL, AR, ID, KS, ME, MS, MO, MT, NV, NC, ND, OH, OR, RI, SC, UT, VA, WV. Population estimates are from the CPS Outgoing Rotation Files. 
Figure A2. Abortion and birth rates for white teens aged 15-19 in 24 states*, by family cap state and years of conception, 1992-1999

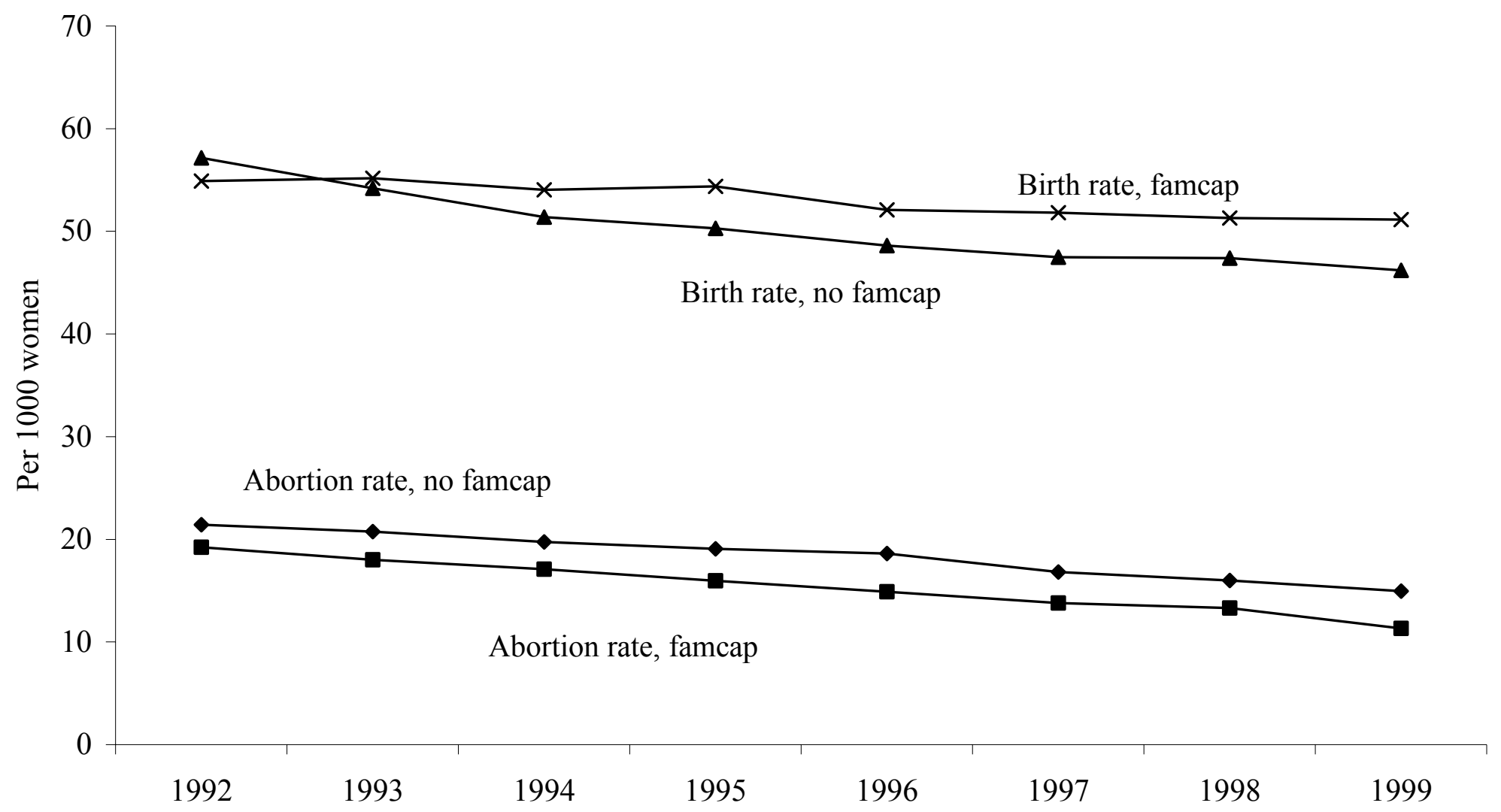

* AL, AZ, AR, HI, ID, KS, ME, MN, MS, MO, MT, NV,NY, NC, ND, OH, OR, RI, SC, TN, TX, UT, VA, WV 
Figure A3. Abortion and birth rates for black teens aged 15-19 in 24 states*, by family cap state and years of conception, 1992-1999

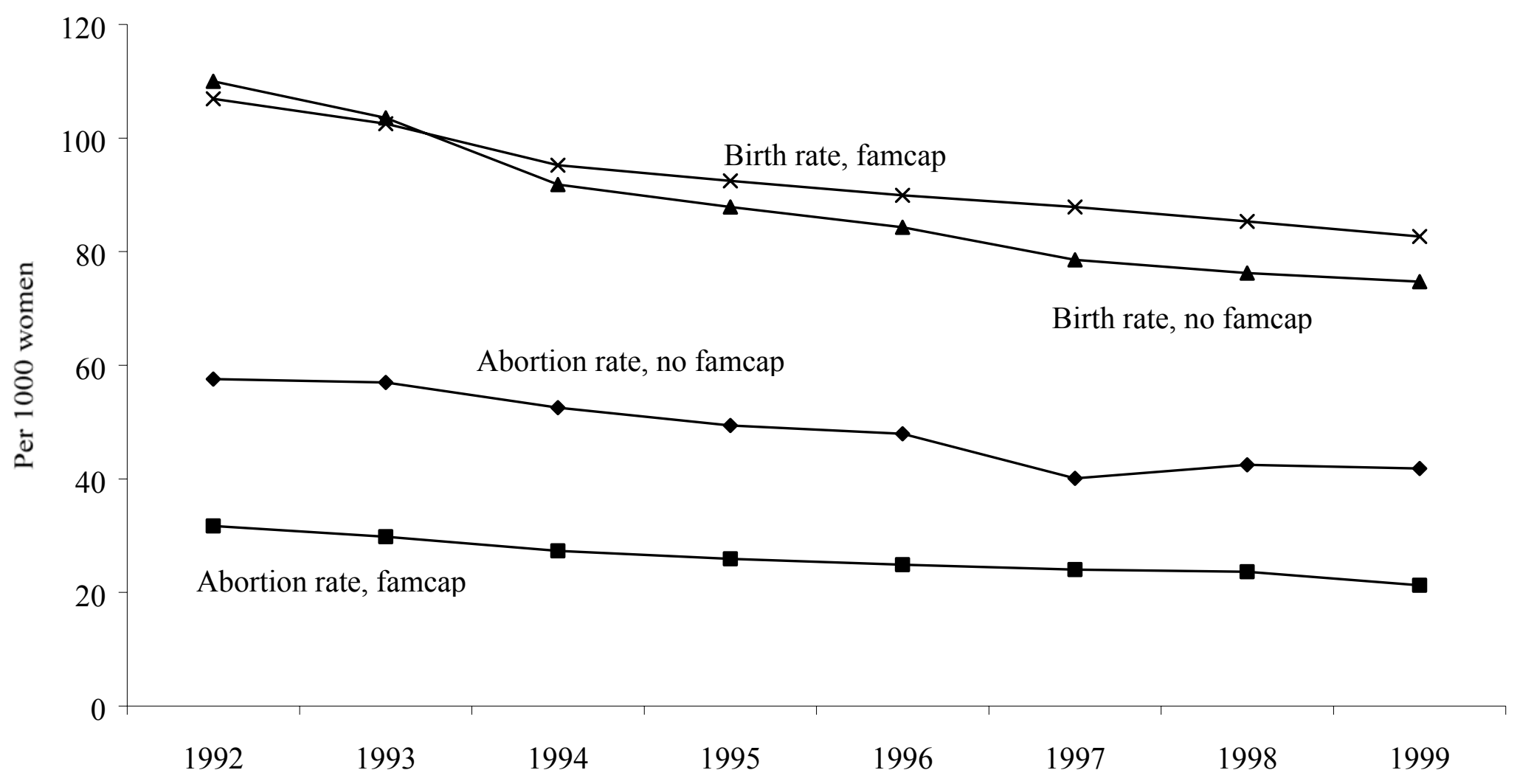

* AL, AZ, AR, HI, ID, KS, ME, MN, MS, MO, MT, NV,NY, NC, ND, OH, OR, RI, SC, TN, TX, UT, VA, WV 